Western University Scholarship@Western

Department of Economics Research Reports

Economics Working Papers Archive

1992

\title{
Liquidity, Exchange Rates, and Business Cycles
}

Wai-Ming Ho

Follow this and additional works at: https://ir.lib.uwo.ca/economicsresrpt

Part of the Economics Commons

Citation of this paper:

Ho, Wai-Ming. "Liquidity, Exchange Rates, and Business Cycles." Department of Economics Research Reports, 9204. London, ON: Department of Economics, University of Western Ontario (1992). 
ISSN : 0318-725X

ISBN : 0-7714-1379-3

\author{
RESEARCH REPORT 9204 \\ LIQUIDITY, EXCHANGE RATES, \\ AND BUSINESS CYCLES \\ by \\ Wai-Ming Ho
}

Apr11 1992

Department of Economics

\title{
Social Science Centre
}

Un1versity of Western Ontario

London. Ontar1o. Canada

N6A $5 \mathrm{C} 2$ 


\title{
Liquidity, Exchange Rates, and Business Cycles
}

\author{
Wai-Ming Ho* \\ Department of Economics \\ University of Western Ontario \\ London, Ontario \\ Canada N6A 5C2
}

Revised March 1992

\begin{abstract}
This paper presents a two-country, two-good, two-currency model to study the role of liquidity effects in exchange rate determination and the international transmission of economic fluctuations. The model provides an exchange rate equation which is different from the simple purchasing-power-parity law of exchange rate determination. Both monetary injections and real disturbances can lead to exchange rate fluctuations and comovements of interest rates, prices and output of the two economies. Whether the covariances of variables in the two countries are positive, negative, or zero depends critically upon the substitutability of the two consumption goods in consumers' preferences.
\end{abstract}

"I would like to thank Steve Williamson for his advice and encouragement. I am also grateful to Paul Gomme, Jeremy Greenwood, Andreas Hornstein, Peter Howitt, and an anonymous referee for their helpful comments. All errors are mine. 


\section{Introduction}

A number of recent studies have provided strong empirical support for the view that positive shocks to money lead to reductions in nominal interest rates and increases in output. For instance, in the U.S. data, Bernanke and Blinder (1990) find evidence consistent with the view that monetary policy works, using innovations to the interest rate on Federal Funds as a measure of changes in monetary policy. Christiano and Eichenbaum (1991) find that the Federal Funds rate is negatively correlated with different measures of monetary growth and with current and future growth rates of output. These observed negative correlations can be interpreted as the results of two opposing effects associated with unanticipated monetary shocks. The first is a liquidity effect, where nominal interest rates fall to induce economic agents to absorb the extra money, which in turn stimulates real activity. The second is an expected inflation effect. If monetary shocks are positively serially correlated, a surprise increase in money supply drives the nominal interest rate up and leads to reductions in employment and output. The evidence suggests that the liquidity effect dominates, at least in the short run.

The liquidity effect is absent in monetary versions of real business cycle models. Money has been introduced into the standard real business cycle model by imposing cash-in-advance constraints on transactions [ as in Greenwood and Huffman (1987), and Cooley and Hansen (1989) ]. These models have only the expected inflation effect, where interest rates rise and output falls in response to a positive monetary shock.

Recently, Lucas (1990) has suggested a methodology to capture liquidity effects in modified versions of cash-in-advance models in which the convenience of the representative household fiction can be retained. In contrast to the transaction-based models of Grossman and Weiss (1983) and Rotemberg (1984), Lucas's methodology can entirely eliminate the problematic wealth redistribution effects induced by monetary shocks, and allows us to isolate the liquidity effects. 
Fuerst (1992) extends Lucas' work by introducing production in the exchange economy of Lucas (1990), to study the link between money and real activity in a closed economy. Monetary injections are assumed to occur through financial intermediaries. Intermediaries channel the newly injected cash to borrowers, and intermediate between borrowers and savers. The crucial assumption is that there is an asymmetry of monetary injections. Savers are unable to alter their deposit decisions after each monetary injection. Only borrowers have access to the newly injected cash through intermediaries. ${ }^{1}$ As a consequence, an unanticipated monetary injection will redistribute purchasing power in favor of borrowers. This redistribution of liquidity will affect real activity by altering the composition of current output, shifting it toward the goods and services borrowers consume. These compositional effects distinguish Fuerst's model from other cash-in-advance models. With the liquidity effects, a monetary shock will also generate fluctuations in asset prices for non-Fisherian reasons.

There are some further studies of liquidity effects as a channel of monetary transmission. Christiano (1991) and Christiano and Eichenbaum (1991) modify Fuerst's model to generate a dominant, persistent liquidity effect so as to improve its ability to confront the data.

This paper is an attempt to study the role of liquidity effects in an open economy, to investigate how they affect the determination of the exchange rate and the international transmission of economic fluctuations, following Fuerst's approach to modelling the asymmetry of monetary injections. The literature on international economics contains many cash-in-advance approaches to exchange rate determination. The two-country general equilibrium models developed in Stockman (1980), Lucas (1982), Helpman and Razin (1985), and Svensson (1985) provide theoretical studies of the determination of prices, interest rates and currency exchange rates with liquidity constraints. However, they did not incorporate the liquidity effects from an asymmetry of monetary injections into their models. In addition, their attention was concentrated mainly on exchange rate determination, and the

\footnotetext{
${ }^{1}$ These assumptions are to capture the institutional fact that corporations have more access to the loans market, while consumers have difficulties in getting credit, and face an interest rate which is much higher than that faced by corporations.
} 
transmission mechanism for fluctuations in output was ignored.

In the literature on the generation and transmission of international business fluctuations, most work studies the transmission of real business cycles [ e.g. Dellas (1986), Cantor and Mark (1987) and (1988) ]. The performance of these open economy real business cycle models is not satisfactory. Backus, Kehoe and Kydland (1991) find that the most striking discrepancy between theory and data concerns the cross-country correlations of consumption and output. In the data, output fluctuations are more highly positively correlated across countries than consumption fluctuations, while the theory predicts the opposite. Some explanations for the low cross-country consumption correlations have been provided by Stockman and Tesar (1990), Tesar (1990), and Devereux, Gregory and Smith (1992), however, these open economy real business cycle models consider only the non-monetary features of the world economy. ${ }^{2}$ The role of monetary disturbances, or more precisely, the role of liquidity effects has not been emphasized in open economy studies.

This paper presents a two-country, two-good, two-currency model to take both exchange rate determination and the transmission of economic fluctuations into consideration. The model is a two-country version of the model in Fuerst (1992). As in Fuerst's model, cash-inadvance constraints are imposed on all transactions. The two countries are linked together by trade in goods and trade in assets. The restrictions of using the sellers' currency for transactions in goods markets and using the buyers' currency for transactions in bonds markets assign intermediaries a role in international trade financing. ${ }^{3}$

An alternative explanation (with monetary features) for the low cross-country consumption correlations is presented in this paper. The particular financial structure imposed in this model seems to be capable of generating lower consumption correlations and higher

\footnotetext{
${ }^{2}$ The low cross-country consumption correlations can be explained by incorporating nontraded goods [ as in Tesar (1990) ], or by introducing taste shocks [ as in Stockman and Tesar (1990) ], or by assuming preferences with non-separability between consumption and labor supply [ as in Devereux, Gregory and Smith (1992) ].

${ }^{3}$ Although Rotemberg (1985) presents a two-country version of the closed economy model in Rotemberg (1984) to examine the connection between money and the terms of trade, it is unable to generate the compositional effects as Fuerst (1992) and this paper do.
} 
output correlations across countries than the usual open economy real business cycle models do. This model focuses attention on the role of international financial markets in allocating liquidity. This particular financial structure prohibits economic agents from insuring themselves against the liquidity risk of dealing with financial intermediaries, and this can lead to a reduction in consumption correlations across countries. Meanwhile, the cash-in-advance constraints restrain labor from being used too intensively when its productivity is high, and this can increase the correlations of output across countries.

This model provides an exchange rate equation with new elements which is different from the usual purchasing-power-parity law of exchange rate determination. Liquidity effects are incorporated into the determination of the exchange rate. Both monetary injections and real disturbances can lead to exchange rate fluctuations and comovements of the interest rates on bonds denominated in either currency, prices and output (employment level) of the two economies. The international transmission mechanism of business fluctuations in this model is different from those of the traditional Mundell-Fleming framework or some recent work on open economy disequilibrium models with sticky goods prices [ e.g. Svensson and van Wijnbergen (1989) ]. In this model, all prices are flexible. In addition to the cash-inadvance constraints, the only rigidity is in the deposit decision of households. By affecting the allocation of liquidity in international financial markets, the effects of the home country's economic disturbances are transmitted to the foreign economy. How the foreign economy responds to these liquidity shocks depends critically upon the substitutability of the two consumption goods in consumers' preferences. This result is similar to that in Svensson and van Wijnbergen (1989), though we have different channels of monetary transmission.

The remainder of the paper is organized as follows. The model is presented in Section 2. A stationary rational expectations equilibrium is described in Section 3. The effects of monetary shocks and productivity disturbances on the world equilibrium are discussed in Section 4. Section 5 is the conclusion. 


\section{The Model}

This is a two-country, two-good, two-currency model, formulated in discrete time with an infinite horizon. The home country and the foreign country have identical constant numbers of infinitely-lived households. All variables will then be expressed in per (own country) household terms. Foreign variables and parameters are indexed with an asterisk $\left(^{*}\right)$.

The infinitely-lived households of each country are identical. The world economy can be considered as an economy with two heterogenous representative households. The objective of the home country representative household is to maximize its expected lifetime utility,

$$
\begin{array}{cl}
E_{0}\left[\sum_{t=0}^{\infty} \beta^{t} U\left(c_{1 t}, c_{2 t}, l_{t}\right)\right], & 0<\beta<1, \\
U\left(c_{1 t}, c_{2 t}, l_{t}\right)=\ln \left[c_{1 t}^{\alpha}+c_{2 t}^{\alpha}\right]^{\frac{1}{\alpha}}+\left[1-l_{t}\right], & \alpha \leq 1,
\end{array}
$$

where $E_{0}$ is the mathematical expectation conditional upon information available in period 0 . The instantaneous utility function $U\left(c_{1 t}, c_{2 t}, l_{t}\right)$ is discounted by the subjective discount factor $\beta$. The consumption of good $j$ in period $t$ is $c_{j t}, j=1,2.4$ Define $\sigma \equiv \frac{1}{1-\alpha}$, to be the constant elasticity of (intratemporal) substitution in consumption between the two goods. In every period, the household is endowed with one unit of time. The household supplies $\boldsymbol{l}_{t}$ units of work effort to the labor market in period $t .^{5}$ Labor is internationally immobile. For simplicity, the representative households of the two countries are assumed to have identical preferences.

There is a complete specialization in production, and trade allows agents in each country

\footnotetext{
${ }^{4}$ Taking the logarithm of the CES utility function of the two consumption goods results in a unit elasticity of intertemporal substitution in consumption, which simplifies the calculation.

${ }^{5} \mathrm{As}$ in Fuerst (1992), the instantaneous utility function is linear in leisure. This assumption is required for simplifying the calculation and obtaining a closed-form solution of the optimisation problem. In addition, this assumption implies a perfectly elastic labor supply curve. As a result, both of the intertemporal and intratemporal responses of labor supply to the economic disturbances are eliminated. Rather than being a drawback, this specification of the utility function allows the model to stress the fluctuations in employment level brought about by shifts in labor demand.
} 
to consume both goods. Firms in the home country produce only good 1, while those of the foreign country produce good 2. The production functions are identical within a country, but different across countries. Each production process requires only labor input. Each of the home firms faces the production function,

$$
\mathcal{F}\left(H_{t}\right)=\theta_{t} H_{t}
$$

where $\theta_{t}$ is the country-wide productivity shock, and $H_{t}$ denotes units of labor employed by the home firm. Similarly, the foreign firm's production function of good 2 is given by $\mathcal{F}^{*}\left(H_{t}^{*}\right)=\theta_{t}^{*} H_{t}^{*}$. With the constant returns technology, perfect competition implies that firms earn zero profits, so that trading in equity claims can be ignored.

\subsection{The Timing of Information and Transactions}

The world economy is a monetary economy with cash-in-advance constraints on all transactions, making use of the methodology suggested by Lucas (1990). This approach allows for the introduction of an asymmetry of monetary injections while retaining the convenience of the representative household fiction. ${ }^{6}$ In this model, each household is composed of five members: a shopper, a worker, a firm, an importer, and a financial intermediary. Cash injections are asymmetric within a household, but symmetric across households of the same country. Injections are asymmetric across countries. Let the beginning-of-period per (own country) household home money stock and foreign money stock be denoted by $M_{t}$ and $M_{t}^{*}$, respectively. From now on, I will use the term "per capita" instead of "per (own country) household" for convenience.

The timing of information and transactions is shown in Figure 1. The representative home country household enters a period with cash balances carried over from last period, which include $M_{h t}$ units of home currency and $M_{f t}$ units of foreign currency. It deposits

\footnotetext{
${ }^{6}$ The international problem is complicated by the fact that the two representative households cannot be treated as a single representative household. In order to eliminate the redistribution of wealth across the two heterogenous households induced by liquidity shocks and to keep the model tractable, the assumptions of no physical capital and no intertemporal trade across countries are required.
} 
$N_{t}$ units of home currency in the home intermediary. Transaction costs are prohibitively high so that once the deposit is made, it cannot be withdrawn until the end of the current period. This assumption is crucial to generate the asymmetry of monetary injections within the household and will be illustrated in more detail below. In addition, for simplicity, the home country household is not allowed to hold foreign currency-denominated deposits. This restriction will not make any qualitative difference to the results.

After the home country deposit is made, the household separates. The shopper takes the remaining $M_{h t}-N_{t}$ units of home currency to the local goods markets. The worker goes to the home labor market. The importer takes the foreign cash balance $M_{f t}$. The firm, the intermediary and the importer go to the financial market where they will meet their counterparts of the foreign country. In the financial market, both home currencydenominated bonds and foreign currency-denominated bonds can be traded. Assume that the number of households of each country is large enough that every individual acts as a price-taker.

Once the household is separated, the state of the world is revealed to everybody. The state of the world, $s_{t}$, is independently and identically distributed across time, and its distribution function $G\left(s_{t}\right)$ is public knowledge. The country-wide productivity shocks, and the monetary injections of each currency from its own country's monetary authority are determined by the state of the world.

Each country has a monetary authority which injects newly issued currency of its own country into the financial market through two channels. The first is by way of lump-sum transfers. The home monetary authority transfers $X_{t}$ units of home currency to each of the home intermediaries. These monetary injections increase the money stock of the economy permanently. The second channel is open market purchases. Each home intermediary is free to choose the quantity of home currency borrowed from the home monetary authority, $Y_{t}$, taking the one-period nominal interest rate, $i_{0 t}$, as given. Given the fixed volume of open market purchases, $\bar{Y}_{t}$, determined by the home monetary authority, the interest rate 
will adjust to clear this market. By assuming these are one-period loans and the monetary authority rebates all of its interest income to its households at the end of the current period, after all transactions are completed, this type of monetary injection is temporary and leaves the end-of-period (beginning-of-period) economy-wide money stock unchanged.

In the goods markets of the home country, the home shopper purchases good 1 and good 2 for consumption subject to the cash-in-advance constraint

$$
M_{h t}-N_{t} \geq P_{1 t} c_{1 t}+P_{2 t} c_{2 t}
$$

where $P_{j t}, j=1,2$, is the price of good $j$, in units of home currency.

In the financial market, each intermediary is assumed to be able to make loans denominated in its own country's currency only, while it is allowed to lend to any firms and importers of both countries. ${ }^{7}$ There are three sources of home currency available to the home intermediary: the deposit by the home household, $N_{t}$, the lump-sum transfer, $X_{t}$, and the borrowings from the home monetary authority, $Y_{t}$. An implicit assumption is that financial intermediaries are not allowed to issue inside money as a medium of exchange. The representative home intermediary has the following cash-in-advance constraint

$$
N_{t}+X_{t}+Y_{t} \geq B_{h t}+Z_{h t}+B_{h t}^{*}+Z_{h t}^{*} \text {. }
$$

Taking the market interest rate on the home currency-denominated bonds, $i_{t}$, and the demand for funds of the foreign borrowers as given, the home intermediary allocates the loans $B_{h t}, Z_{h t}, B_{h t}^{*}$ and $Z_{h t}^{*}$ to the home firm, the home importer, the foreign firm and the foreign importer, respectively.

The home firm borrows $B_{h t}$ units of home currency from the home intermediary and $B_{f t}$ units of foreign currency from the foreign intermediary. The home importer borrows $Z_{h t}$ units of home currency from the home intermediary and $Z_{f t}$ units of foreign currency

\footnotetext{
${ }^{7}$ That is, it is assumed that each bond is denominated in the currency of the lender's country. This assumption is for simplicity. Even if we let intermediaries borrow from the intermediaries of another country, then lend to their borrowers, the equilibrium will not be affected. But many accounting procedures will be involved.
} 
from the foreign intermediary. However, home firms have to pay the home workers in home currency, while home importers have to pay the foreign firms in foreign currency. Their foreign counterparts also face a similar problem. At this time, the foreign exchange market is opened so that the firms and the importers of both countries can trade for the desired currency. Assume that a flexible exchange rate regime is adopted by the two countries. Let $\hat{e}_{t}$ be the exchange rate at the beginning of the period, after the state of the world $s_{t}$ is known. This exchange rate will adjust to clear the foreign exchange market.

In addition, firms and importers of the same country may trade bonds with each other. These bonds may be either home currency-denominated or foreign currency-denominated. They are not allowed to trade bonds with the firms or importers of another country. Only intermediaries are assumed to have the expertise to deal with the borrowers of other countries. However, in equilibrium, the net supply of the bonds traded among firms and importers of the same country will be zero in this representative agent economy. Thus, it does not matter whether these kinds of asset trading among firms and importers of the same country are allowed or not. But for deriving the asset pricing rules, two kinds of asset trading will be considered. The first is the trading of home currency-denominated bonds among the home firms. The second is the trading of foreign currency-denominated bonds among the home importers. The representative home firm purchases $K_{h t}$ units of the one-period, one-unit home currency-denominated bonds, issued by other home firms, at the price of $q_{t}=\frac{1}{1+i_{t}}$ units of home currency. Similarly, the representative home importer purchases $K_{f t}$ units of the one-period, one-unit foreign currency-denominated bonds, issued by other home importers, at the price of $q_{t}^{*}=\frac{1}{1+i_{i}^{*}}$ units of foreign currency.

The home firm then takes the home currency obtained after asset trading, $B_{h t}+B_{f t} \hat{e}_{t}-$ $K_{h t}\left(\frac{1}{1+i_{t}}\right)$, to the home labor market, hires $H_{t}$ units of labor at the market wage rate, $W_{t}$, to produce good 1 according to the production function given by equation (2). The cash-inadvance constraint of the home firm is given by 


$$
B_{h t}+B_{f t} \hat{e}_{t}-K_{h t}\left(\frac{1}{1+i_{t}}\right) \geq W_{t} H_{t}
$$

The output will be shipped to the home market of good 1 and sold to home shoppers and foreign importers at the price of $P_{1 t}$ units of home currency. The home worker receives his wage, $W_{t} l_{t}$, and goes home to enjoy his leisure, $1-l_{t}$.

The home importer goes to the foreign goods markets with the cash balances obtained after the asset trading, $M_{f t}+Z_{f t}+\frac{Z_{h s}}{\dot{\varepsilon}_{t}}-K_{f t}\left(\frac{1}{1+i_{t}^{i}}\right)$, purchases foreign goods at the price of $P_{2 t}^{*}$ units of foreign currency, and sells them to home shoppers at the price of $P_{2 t}$ units of home currency in the home market for good 2. Thus, the cash-in-advance constraint for the home importer is

$$
M_{f t}+Z_{f t}+\frac{Z_{h t}}{\hat{e}_{t}}-K_{f t}\left(\frac{1}{1+i_{t}^{*}}\right) \geq P_{z t}^{*} c_{2 t} .
$$

At the end of the period, loan repayments are made. ${ }^{8}$ However, the home borrowers do not have foreign currency to repay the loans from the foreign intermediaries, while the foreign borrowers do not have home currency to repay the loans from the home intermediaries. It is assumed that the transaction costs in the foreign exchange market are significantly less than in the loans market so that currency trading can be more frequent than other asset trading. ${ }^{9}$ Consequently, only the foreign exchange market can be reopened at the end of the period. Borrowers can trade for the currency they need for repaying their foreign debts. ${ }^{10}$ The end-of-period exchange rate, $e_{t}$, responds to clear this foreign exchange market. After all transactions are completed, the household is reunited, all remaining cash is pooled, and goods purchased by the shopper are consumed. The home monetary authority rebates its interest income to the home representative household as a lump-sum transfer, $\Gamma_{t}$. The

\footnotetext{
${ }^{8}$ Whether the loan repayments are made at the end of the current period or in the next period before the borrowers obtain their new loans makes no difference to our analysis.

${ }^{9}$ This assumption is also used by Helpman and Rasin (1982) and Svensson (1985). Svensson (1985) calls this "continuous currency trade".

${ }^{10}$ Since the cash-in-advance constraints are imposed, borrowers are always able to repay their debts. The market-clearing condition of the foreign exchange market implies that there is no intertemporal trade across countries in every period, which helps to focus our discussion on the role of liquidity effects.
} 
household then holds the remaining cash balances $M_{h t+1}$ and $M_{f t+1}$ for next period, where

$$
\begin{aligned}
M_{h t+1}= & M_{h t}+X_{t}-Y_{t} i_{0 t}+P_{1 t} \mathcal{F}\left(H_{t}\right)-P_{1 t} c_{1 t}-W_{t} H_{t}+W_{t} l_{t}+B_{f t} \hat{e}_{t}-Z_{h t} \\
& +\left(B_{h t}^{*}+Z_{h t}^{*}\right) i_{t}-\left(B_{f t}+Z_{f t}\right)\left(1+i_{t}^{*}\right) e_{t}+K_{h t}\left(\frac{i_{t}}{1+i_{t}}\right)+\Gamma_{t}, \\
M_{f t+1}= & M_{f t}+Z_{f t}+\frac{Z_{h t}}{\hat{e}_{t}}+K_{f t}\left(\frac{i_{t}^{*}}{1+i_{t}^{*}}\right)-P_{2 t}^{*} c_{2 t} .
\end{aligned}
$$

Due to the assumptions of a flexible exchange rate regime and no debts carried over periods, the current account of each country is always balanced. ${ }^{11}$ Let $\Lambda_{t}=\left(\theta_{t}, X_{t}, \bar{Y}_{t}, \Gamma_{t}\right)$ and $\mathcal{P}_{t}=\left(P_{1 t}, P_{2 t}, i_{t}, i_{0 t}, i_{t}^{*}, W_{t}, \hat{e}_{t}, e_{t}\right)$ denote the vector of the economic disturbances and the vector of the market prices faced by the home representative household, respectively.

The activities of the foreign representative household are analogous to those of the home representative household, and the foreign variables and parameters are defined in a similar way.

\subsection{The Optimization Problem of the Home Representative Household}

The home representative household faces the following dynamic optimization problem. Also, it is noted that there is an analogous optimization problem for the foreign representative household, which is presented in the appendix.

Given the distribution function $G$ and the collection of sequences

$\left\{\Lambda_{t}, \mathcal{P}_{t}, M_{t}, M_{t}^{*}, M_{h t}^{*}, M_{f t}^{*}, B_{h t}^{*}, Z_{h t}^{*}\right\}_{t=0}^{\infty}$,

the home representative household chooses the collection of sequences

$$
\left\{N_{t}, c_{1 t}, c_{2 t}, Y_{t}, B_{h t}, Z_{h t}, B_{f t}, Z_{f t}, l_{t}, H_{t}, K_{h t}, K_{f t}\right\}_{t=0}^{\infty} \text {. }
$$

to maximize the expected lifetime utility with preferences given by (1) and (2), subject to the technology constraint (3), the cash-in-advance constraints (4)-(7), and the two evolution equations of the household's beginning-of-period cash balances (8) and (9).

\footnotetext{
${ }^{11}$ In this model, the existence of the cash-in-advance constraints implies that the current account consists of trade in goods and trade in financial services. Each household not only purchases the goods of another country but also employs the financial services provided by the intermediaries of that country.
} 
In restricting the discussion to stationary rational expectations equilibrium, in which the prices and decision rules are fixed functions of the state of the world, $s_{t}$, and the ratio of the beginning-of-period per capita money stocks of the two countries, $\delta_{t} \equiv \frac{M_{i}^{*}}{M_{t}}$, we have to rescale the nominal variables. Every nominal variable is divided by the beginning-of-period per capita money stock of its own country. That is, normalize the beginning-of-period per capita money stock of each country at unity. Let lowercase letters represent the rescaled values. For instance, the vector of the economic disturbances and the vector of the market prices faced by the home representative household are now denoted by $\lambda_{t}=\left(\theta_{t}, x_{t}, \bar{y}_{t}, \gamma_{t}\right)$ and $p_{t}=\left(p_{1 t}, p_{2 t}, i_{t}, i_{0 t}, i_{t}^{*}, w_{t}, \hat{e}_{t}, e_{t}\right)$, respectively. Dynamic programming can be applied to solve the household's optimization problem. Define the value function corresponding to the household's problem $J(m, \delta, \tilde{s})$ by

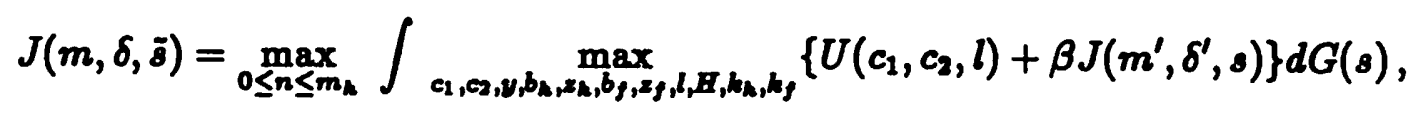

subject to

$$
\begin{aligned}
& m_{h}-n \geq p_{1} c_{1}+p_{2} c_{2}, \\
& n+x+y \geq b_{h}+z_{h}+b_{h}^{*}+z_{h}^{*}, \\
& b_{h}+b_{f} \hat{e} \delta-k_{h}\left(\frac{1}{1+i}\right) \geq w H, \\
& m_{f}+z_{f}+\frac{z_{h}}{\hat{e} \delta}-k_{f}\left(\frac{1}{1+i^{*}}\right) \geq p_{2}^{*} c_{2}, \\
& m_{h}^{\prime}=\frac{1}{1+x}\left[m_{h}+x-y i_{0}+p_{1} \mathcal{F}(H)-p_{1} c_{1}-w H+w l+b_{f} \hat{e} \delta-z_{h}\right. \\
&\left.+\left(b_{h}^{*}+z_{h}^{*}\right) i-\left(b_{f}+z_{f}\right)\left(1+i^{*}\right) e \delta+k_{h}\left(\frac{i}{1+i}\right)+\gamma\right], \\
& m_{f}^{\prime}=\frac{1}{1+x^{*}}\left[m_{f}+z_{f}+\frac{z_{h}}{\hat{e} \delta}+k_{f}\left(\frac{i^{*}}{1+i^{*}}\right)-p_{2}^{*} c_{2}\right],
\end{aligned}
$$

where the time subscripts for current period have been omitted while those for the next period have been replaced by primes. The realization of last period's state of the world is $\tilde{\boldsymbol{s}}$. The collection of the beginning-of-period money holdings of the home and foreign 
representative households is represented by $m=\left(m_{h}, m_{f}, m_{h}^{*}, m_{f}^{*}\right)$. The growth rates of the beginning-of-period per capita money stocks of the home and the foreign country are denoted by $x$ and $x^{*}$, respectively. It is noted that the decision for $n$ is made before the realization of the state of the world $s$. Thus, $n$ is independent of $s$.

Let $\mu_{1}, \mu_{2}, \mu_{3}$ and $\mu_{4}$ be the multipliers associated with the cash-in-advance constraints $\left(4^{\prime}\right)-\left(7^{\prime}\right)$ respectively. Necessary conditions for the home representative household are:

$$
\begin{aligned}
E\left[\mu_{1}(s)\right] & =E\left[\mu_{2}(s)\right] \\
\frac{U_{1}(s)}{p_{1}(s)} & =\frac{U_{2}(s)}{p_{2}(s)}=\frac{1}{1-n} \\
\frac{U_{1}(s)}{p_{1}(s)} & =\mu_{1}(s)+\frac{1}{1+x(s)} \beta E\left[\frac{U_{1}\left(s^{\prime}\right)}{p_{1}\left(s^{\prime}\right)}\right] \\
-U_{l}(s) & =\frac{w(s)}{1+x(s)} \beta E\left[\frac{U_{1}\left(s^{\prime}\right)}{p_{1}\left(s^{\prime}\right)}\right] \\
w(s)[1+i(s)] & =p_{1}(s) \mathcal{F}^{\prime}(H(s)) \\
\mu_{2}(s) & =\mu_{3}(s)=\frac{i(s)}{1+x(s)} \beta E\left[\frac{U_{1}\left(s^{\prime}\right)}{p_{1}\left(s^{\prime}\right)}\right] \\
\mu_{h}(s) & =\frac{i^{*}(s) e(s) \delta}{1+x(s)} \beta E\left[\frac{U_{1}\left(s^{\prime}\right)}{p_{1}\left(s^{\prime}\right)}\right] \\
\frac{1}{n+x(s)+b_{f}(s)} & \hat{e}(s) \delta \geq w(s) H(s) \\
m_{h}(s) & -n \geq p_{1}(s) c_{1}(s)+p_{2}(s) c_{2}(s) \quad \text { with equality if } \mu_{3}(s)>0 \\
e(s)\left[1+i^{*}(s)\right] & b_{h}(s)+z_{h}(s)+b_{h}^{*}(s)+z_{h}^{*}(s) \quad \text { with equality if } \mu_{2}(s)>0
\end{aligned}
$$




$$
m_{f}(s)+z_{f}(s)+\frac{z_{h}(s)}{\hat{e}(s) \delta} \geq p_{2}^{*}(s) c_{2}(s) \quad \text { with equality if } \mu_{4}(s)>0
$$

where the ratio $1 /[1+x(s)]$ is for rescaling the values relative to next period's beginning-ofperiod per capita money stock rather than the current one. Arbitrage implies $i(s)=i_{0}(s)$. Also, as mentioned above, $K_{h}(s)=K_{f}(s)=0 \quad \forall s$ in equilibrium. These have been substituted into the necessary conditions.

Equation (10) is the first-order condition for deposits. The expected marginal utility from one unit of home currency allocated to the shopper, $E\left(\mu_{1}\right)$, must be equal to the expected marginal utility from one unit of home currency-denominated deposit put into the financial market, $E\left(\mu_{2}\right)$.

Equation (11) is the usual first-order condition for intratemporal allocation of consumption. Equations (12)-(14) are the intertemporal first-order conditions for consumption, labor supply and labor demand, respectively. The effective wage rate faced by the firm is $w(s)[1+i(s)]$. Equation (12) shows that the existence of a binding liquidity constraint drives a wedge between the marginal utility of consumption and the discounted expected marginal utility of consumption of next period.

Equation (15) is the first-order condition for borrowing from the home intermediary. The marginal utility of one unit of home currency in the financial market, $\mu_{2}$, should equal the marginal utility from one unit of home currency allocated to the home firm, $\mu_{3}$, which should also equal the discounted expected marginal utility derived from the interest payment, $i(s)$. Equation (16) is the first-order condition for borrowing from the foreign intermediary. The marginal utility from the use of one unit of foreign currency, $\mu_{4}$, and the discounted expected marginal utility loss from the interest payment paid at the end of current period must be equalized. Equation (17) is the first-order condition for the home borrowers to borrow from both intermediaries. That is, they are indifferent between issuing bonds denominated in either currency of the two countries. It must be the case that, the price of a one-period, 
one-unit home currency-denominated bond, $\frac{1}{1+i(0)}$, is equal to the price of the one-period, foreign currency-denominated bond with face value equivalent to one unit of home currency, measured in terms of home currency, $\frac{a(\varphi)}{e(0)\left[1+i^{\circ}(0)\right]}$. This implies that the cost of borrowing home currency directly from the home intermediary is equal to the effective cost of borrowing foreign currency from the foreign intermediary, and then obtaining home currency through foreign exchange. Arbitrage ensures that this condition always holds. So it is also an arbitrage condition of the financial market.

Equations (4")-(7") are the standard complementary slackness conditions. If the cashin-advance constraints are non-binding, their associated multipliers (shadow prices of the marginal units of currency in their corresponding markets.) will be zero.

\section{Asset Pricing}

From the necessary conditions (12), (15) and (16), the asset pricing rules can be derived.

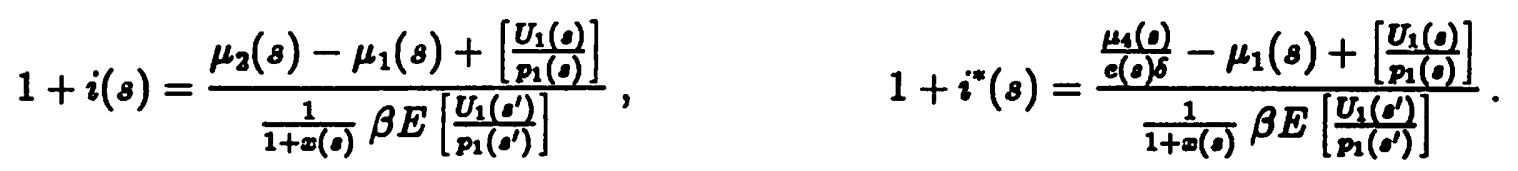

If the terms $\left[\mu_{2}(s)-\mu_{1}(s)\right]$ and $\left[\frac{\mu_{1}(\theta)}{e(s) b}-\mu_{1}(s)\right]$ did not exist in these pricing equations, they will become the standard asset pricing equations. ${ }^{12}$ However, the cash-in-advance constraints on all transactions make the prices of financial assets (interest rates) quite different from those predicted on the basis of Fisherian fundamentals. The term $\left[\mu_{2}(s)-\mu_{1}(s)\right]$ is the difference of the values (in terms of utility) of one unit of home currency in the financial market and in the home good market. ${ }^{13}$ If $\mu_{2}(s)$ is larger than $\mu_{1}(s)$, that means that the home

\footnotetext{
${ }^{12}$ In the standard model, [e.g. Lucas (1978)], the representative agent is assumed to maximise time-additive expected utility $E_{0}\left\{\sum_{t=0}^{\infty} \beta^{t} \delta\left(c_{t}\right)\right\}$, where $E_{0}$ denotes the expectation conditional on information at time $0, \beta$ is the subjective discount factor, $U$ is the instantaneous utility function, and $c_{t}$ is consumption. This model implies that the price of an asset is the representative agent's rational expectation of future returns multiplied by the marginal rate of substitution between present and future consumption - the Fisherian fupdamentals of interest rate determination.

13 As the household has to choose $n$ before the realisation of the current state of the world is revealed, an optimal decision requires that the expected values, $E\left[\mu_{1}(s)\right]$ and $E\left[\mu_{2}(s)\right]$, must be equalised. Thus the term $\left[\mu_{2}(s)-\mu_{1}(s)\right] \neq 0$ represents a forecasting error.
} 
goods markets is relatively more liquid than the home currency-denominated bonds market. Then, the price of the home currency-denominated bonds will be relatively lower than that implied by Fisherian fundamentals. There are two effects determining $i(s)$, which are the liquidity effect, represented by $\left[\mu_{2}(s)-\mu_{1}(s)\right]$, and the expected price effect, represented by $[1+x(s)] p_{1}\left(s^{\prime}\right) .{ }^{14}$ These two effects act in opposite directions which generate the ambiguity of the movements of the interest rate.

Similarly, $\mu_{4}(s)$ reflects the level of liquidity in the foreign currency-denominated bond market. For comparing with $\mu_{1}(s)$, it has to be adjusted by the exchange rate $e(s)$ and the ratio $\delta$. It is obvious that the prices of the home currency-denominated bonds and the foreign currency-denominated bonds are in general different. The only case where they are equalized is $\mu_{2}(s)=\frac{\mu_{1}(0)}{(c) 6}$. That is, the two bonds markets are equally liquid. However, there is no mechanism to equate them, so this condition does not necessarily hold. Arbitrage ensures the effective costs of financing in these two markets to be identical, that is, equation (17) holds, rather than equalizes the nominal interest rates, $i(s)$ and $i^{*}(s)$. The price of a home currency-denominated bond will be higher if its market is relatively more liquid than that of a foreign currency-denominated bond. In addition, the beginning-of-period exchange rate will be higher than the end-of-period exchange rate, $\hat{e}(s)>e(s)$, and the home currency will appreciate. These exchange rates will be equal only when $i(s)$ and $i^{*}(s)$ are the same. Thus, in this model, monetary injections cause not only fluctuations and differentials of the interest rates in the two bonds markets for non-Fisherian reasons but also exchange rate fluctuations. ${ }^{15}$

\footnotetext{
${ }^{11}$ The increase in the money supply results in an expected one-time jump in next period's prices. In addition, there will be an expected inflation effect if money growth rates are positively serially correlated.

${ }^{15}$ It is noted that the beginning-of-period exchange rate in period $t+1, \hat{e}_{t+1}$, has incorporated the information about $s_{t+1}$ which is not available in period $t$. Thus $\hat{e}_{t+1}$ is in general different from the end-of-period exchange rate in period $t, e_{\ell}$. The exchange rate may fluctuate both within a period and across periods.
} 


\section{Stationary Rational Expectations Equilibrium}

In the stationary rational expectations equilibrium of the world economy, the prices and decision rules are fixed functions of the ratio of the beginning-of-period per capita money stocks of the two countries, $\delta$, and the state of the world, s. Note that $n$ and $n^{*}$ are independent of $s$. They depend on $\delta$ only. As mentioned above, $k_{j t}=k_{j t}^{*}=0, j=h, f, \forall t$, in equilibrium. From now on, they will be omitted in the following discussion. An equilibrium is defined as follows:

Definition: An equilibrium is a set of initial conditions $\left\{m_{h 0}, m_{f 0}, m_{h 0}^{*}, m_{f 0}^{*}\right\}$, and a collection of sequences

$\left\{\lambda_{t}, \lambda_{t}^{*}, p_{t}, p_{t}^{*}, m_{t}, n_{t}, y_{t}, b_{h t}, b_{f t}, z_{h t}, z_{f t}, c_{1 t}, c_{2 t}, l_{t}, H_{t}, n_{t}^{*}, y_{t}^{*}, b_{h t}^{*}, b_{f t}^{*}, z_{h t}^{*}, z_{f t}^{*}, c_{1 t}^{*}, c_{2 t}^{*}, l_{t}^{*}, H_{t}^{*}\right\}_{t=0}^{\infty}$, such that

(1) Given $\left\{\lambda_{t}, p_{t}, m_{h t}^{*}, m_{f t}^{*}, b_{h t}^{*}, z_{h t}^{*}\right\}_{t=0}^{\infty},\left\{n_{t}, c_{1 t}, c_{2 t}, y_{t}, b_{h t}, b_{f t}, z_{h t}, z_{f t}, b_{t}, H_{t}\right\}_{t=0}^{\infty}$ solve the home representative household's optimization problem (1') subject to $\left(4^{\prime}\right)-\left(9^{\prime}\right)$.

Given $\left\{\lambda_{t}^{*}, p_{t}^{*}, m_{h t}, m_{f t}, b_{f t}, z_{f t}\right\}_{t=0}^{\infty}, \quad\left\{n_{t}^{*}, c_{i t}^{*}, c_{2 t}^{*}, y_{t}^{*}, b_{h t}^{*}, b_{f t}^{*}, z_{h t}^{*}, z_{f t}^{*}, l_{t}^{*}, H_{t}^{*}\right\}_{t=0}^{\infty}$ solve the analogous optimization problem of the foreign representative household subject to the constraints.

(2) The budget constraint of the each country's monetary authority must be satisfied. The monetary injections are financed by printing money. The lump sum rebates of interest income must satisfy

$$
\begin{gathered}
\gamma_{t}=y_{t} i_{t} \\
\gamma_{t}^{*}=y_{t}^{*} i_{t}^{*}
\end{gathered}
$$

(3) All markets are cleared.

Goods markets

$$
\begin{aligned}
& c_{1 t}+c_{1 t}^{*}=\theta_{t} H_{t}, \\
& c_{2 t}+c_{2 t}^{*}=\theta_{t}^{*} H_{t}^{*} .
\end{aligned}
$$


Labor markets

$$
\begin{aligned}
& l_{t}=H_{t}, \\
& l_{t}^{*}=H_{t}^{*} .
\end{aligned}
$$

Financial markets

(i) open market purchases

$$
\begin{aligned}
& y_{t}=\bar{y}_{t}, \\
& y_{t}^{*}=\bar{y}_{t}^{*},
\end{aligned}
$$

(ii) money markets

$$
\begin{aligned}
& m_{h t}+m_{h t}^{*}=1, \\
& m_{f t}+m_{f t}^{*}=1,
\end{aligned}
$$

(iii) loans markets

$$
\begin{aligned}
& n_{t}+x_{t}+y_{t}=b_{h t}+z_{h t}+b_{h t}^{*}+z_{h t}^{*}, \\
& n_{t}^{*}+x_{t}^{*}+y_{t}^{*}=b_{f t}+z_{f t}+b_{f t}^{*}+z_{f t}^{*},
\end{aligned}
$$

(iv) foreign exchange market

$$
\begin{aligned}
\left(b_{h t}^{*}+z_{h t}\right) & =\hat{e}_{t} \delta_{t}\left(b_{f t}+z_{f t}^{*}\right), \\
\left(b_{h t}^{*}+z_{h t}^{*}\right)\left(1+i_{t}\right) & =e_{t} \delta_{t}\left(b_{f t}+z_{f t}\right)\left(1+i_{t}^{*}\right) .
\end{aligned}
$$

(4) Arbitrage conditions hold.

$$
\hat{e}_{t}\left(1+i_{t}\right)=e_{t}\left(1+i_{t}^{*}\right),
$$

$$
\frac{p_{2 t}}{p_{1 t}}=\left(1+i_{t}\right)\left(1+i_{t}^{*}\right) \frac{p_{2 t}^{*}}{p_{1 t}^{*}}
$$




$$
\begin{aligned}
& p_{1 t}^{*}=\frac{p_{1 t}\left(1+i_{t}\right)}{e_{t} \delta_{t}} \\
& p_{2 t}=p_{2 t}^{*}\left(1+i_{t}^{*}\right) e_{t} \delta_{t} .
\end{aligned}
$$

This completes the definition of equilibrium.

As shown in equation (32), because of the cash-in-advance constraints for importers, the terms of trade faced by the two representative households are different. So given the same instantaneous utility function, for any value of $\sigma \neq 0$, the consumption ratios are different, $\left(c_{1 t} / c_{2 t}\right)>\left(c_{1 t}^{*} / c_{2 t}^{*}\right), \forall t$, if any nominal interest rate is positive. Each representative household consumes more domestic goods and less imported goods than its trading partner.

\section{The Determination of the Exchange Rate}

In this model, the exchange rate is determined simultaneously with the home price of good 1 and the foreign price of good 2. The exchange rate responds to clear the foreign exchange market by equating the supply and demand for foreign exchange of the two countries. Assume that nominal interest rates for bonds denominated in either currency of the two countries are positive in all states, so that the cash-in-advance constraints for the intermediaries, firms and importers of the two countries are always binding. By combining equations (17'), (30) and (31) with the following binding constraints for the firm and the importer of each country,

$$
\begin{aligned}
& b_{t} \equiv b_{h t}+b_{f t} \hat{e}_{t} \delta_{t}=w_{t} l_{t} \\
& z_{t} \equiv \frac{z_{h t}}{\hat{e}_{t} \delta_{t}}+z_{f t}=p_{2 t}^{*} c_{2 t} \\
& b_{t}^{*} \equiv \frac{b_{h t}^{*}}{\hat{e}_{t} \delta_{t}}+b_{f t}^{*}=w_{t}^{*} l_{t}^{*}
\end{aligned}
$$




$$
z_{t}^{*} \equiv z_{h t}^{*}+z_{f t}^{*} \hat{e}_{t} \delta_{t}=p_{1 t} c_{1 t}^{*}
$$

the exchange rate equations can be derived,

$$
\begin{aligned}
& \hat{e}_{t}=\frac{P_{1 t} c_{1 t}^{*}}{P_{2 t}^{*} c_{2 t}}=\frac{1}{\delta_{t}}\left[\frac{\left(x_{t}+y_{t}+n_{t}\right)\left(1+i_{t}\right)-\left(1-n_{t}\right)}{\left(x_{t}^{*}+y_{t}^{*}+n_{t}^{*}\right)\left(1+i_{t}^{*}\right)-\left(1-n_{t}^{*}\right)}\right] \\
& e_{t}=\frac{\left(1+i_{t}\right)}{\left(1+i_{t}^{*}\right)} \hat{e}_{t}=\frac{\left(1+i_{t}\right) P_{1 t} c_{1 t}^{*}}{\left(1+i_{t}^{*}\right) P_{2 t}^{*} c_{2 t}}=\frac{P_{2 t} c_{2 t}}{P_{1 t}^{*} c_{1 t}^{*}}
\end{aligned}
$$

where $b_{t}, z_{t}, b_{t}^{*}$ and $z_{t}^{*}$ are the ultimate demands for currency of the home firm, the home importer, the foreign firm, and the foreign importer, respectively.

Equation (39) states that $\hat{e}_{t}$ is determined by the relative quantities of the two currencies used in international trade financing, $\left(P_{1 t} c_{1 t}^{*}\right) /\left(P_{2 t}^{*} c_{2 t}\right)$, where

$$
\begin{aligned}
& P_{1 t} c_{1 t}^{*}=M_{t} p_{1 t} c_{1 t}^{*}=M_{t}\left[\left(x_{t}+y_{t}+n_{t}\right)\left(1+i_{t}\right)-\left(1-n_{t}\right)\right] \\
& P_{2 t}^{*} c_{2 t}=M_{t}^{*} p_{2 t}^{*} c_{2 t}=M_{t}^{*}\left[\left(x_{t}^{*}+y_{t}^{*}+n_{t}^{*}\right)\left(1+i_{t}^{*}\right)-\left(1-n_{t}^{*}\right)\right]
\end{aligned}
$$

Define $\Omega_{t} \equiv\left(x_{t}+y_{t}+n_{t}\right)$ and $\Omega_{t}^{*} \equiv\left(x_{t}^{*}+y_{t}^{*}+n_{t}^{*}\right)$, which are the supplies of loanable funds in the markets for home currency-denominated bonds and the foreign currency-denominated bonds, respectively. As $n_{t}$ and $n_{t}^{*}$ are independent of the realization of the current state of the world, $s_{t}$, the exchange rate, $\hat{e}_{t}$, depends only upon how the two terms, $\Omega_{t}\left(1+i_{t}\right)$ and $\Omega_{t}^{*}\left(1+i_{t}^{*}\right)$, are affected by $s_{t}$.

$$
\begin{aligned}
& \frac{1}{\Omega_{t}\left(1+i_{t}\right)} \frac{d\left[\Omega_{t}\left(1+i_{t}\right)\right]}{d s_{t}}=\frac{1}{\Omega_{t}} \frac{d \Omega_{t}}{d s_{t}}+\frac{1}{\left(1+i_{t}\right)} \frac{d i_{t}}{d s_{t}} \\
& \frac{1}{\Omega_{t}^{*}\left(1+i_{t}^{*}\right)} \frac{d\left[\Omega_{t}^{*}\left(1+i_{t}^{*}\right)\right]}{d s_{t}}=\frac{1}{\Omega_{t}^{*}} \frac{d \Omega_{t}^{*}}{d s_{t}}+\frac{1}{\left(1+i_{t}^{*}\right)} \frac{d i_{t}^{*}}{d s_{t}}
\end{aligned}
$$


If the home country's monetary authority's injections of cash, by way of changes in either $x_{t}$ or $y_{t}$, are the only economic disturbances in the world economy, we have

$$
\begin{aligned}
& \frac{\Omega_{t}}{\Omega_{t}\left(1+i_{t}\right)} \frac{d\left[\Omega_{t}\left(1+i_{t}\right)\right]}{d \Omega_{t}}=1+\frac{\Omega_{t}}{\left(1+i_{t}\right)} \frac{d i_{t}}{d \Omega_{t}} \\
& \frac{\Omega_{t}}{\Omega_{t}^{*}\left(1+i_{t}^{*}\right)} \frac{d\left[\Omega_{t}^{*}\left(1+i_{t}^{*}\right)\right]}{d \Omega_{t}}=\frac{\Omega_{t}}{\left(1+i_{t}^{*}\right)} \frac{d i_{t}^{*}}{d \Omega_{t}}
\end{aligned}
$$

where $\frac{\Omega_{t}}{n_{t}\left(1+i_{t}\right)} \frac{d\left[\Omega_{t}\left(1+i_{i}\right)\right]}{d \Omega_{t}}$ and $\frac{\Omega_{t}}{n_{i}^{*}\left(1+i_{i}\right)} \frac{d\left[\Omega_{i}^{*}\left(1+i_{i}^{i}\right)\right]}{d n_{t}}$ are the elasticities of the changes in $\Omega_{t}\left(1+i_{t}\right)$ and $\Omega_{t}^{*}\left(1+i_{t}^{*}\right)$ with respect to the changes in $\Omega_{t}$, respectively. The elasticities of the changes in the gross interest rates, $\left(1+i_{t}\right)$ and $\left(1+i_{t}^{*}\right)$, with respect to the changes in $\Omega_{t}$ are denoted by $\frac{\Omega_{t}}{\left(1+i_{t}\right)} \frac{d i_{i}}{d n_{t}}$ and $\frac{\Omega_{t}}{\left(1+i_{t}^{*}\right)} \frac{d i_{i}^{*}}{d n_{t}}$, respectively.

Similarly, if the home country's productivity shock is the only economic disturbance in the world economy, we have

$$
\begin{aligned}
& \frac{\theta_{t}}{\Omega_{t}\left(1+i_{t}\right)} \frac{d\left[\Omega_{t}\left(1+i_{t}\right)\right]}{d \theta_{t}}=\frac{\theta_{t}}{\left(1+i_{t}\right)} \frac{d i_{t}}{d \theta_{t}} \\
& \frac{\theta_{t}}{\Omega_{t}^{*}\left(1+i_{t}^{*}\right)} \frac{d\left[\Omega_{t}^{*}\left(1+i_{t}^{*}\right)\right]}{d \theta_{t}}=\frac{\theta_{t}}{\left(1+i_{t}^{*}\right)} \frac{d i_{t}^{*}}{d \theta_{t}}
\end{aligned}
$$

The elasticities of the changes in $\Omega_{t}\left(1+i_{t}\right)$ and $\Omega_{t}^{*}\left(1+i_{t}^{*}\right)$ with respect to the changes in $\theta_{t}$ are denoted by $\frac{\theta_{t}}{n_{t}\left(1+i_{t}\right)} \frac{d\left[\Omega_{t}\left(1+i_{i}\right)\right]}{d \theta_{t}}$ and $\frac{\theta_{t}}{n_{i}^{*}\left(1+i_{i}^{i}\right)} \frac{d\left[\Omega_{i}^{*}\left(1+i_{i}\right)\right]}{d \theta_{t}}$, respectively. The elasticities of the changes in the gross interest rates, $\left(1+i_{t}\right)$ and $\left(1+i_{t}^{*}\right)$, with respect to the changes in $\theta_{t}$ are denoted by $\frac{\theta_{t}}{\left(1+i_{t}\right)} \frac{d i_{s}}{d \theta_{t}}$ and $\frac{\theta_{t}}{\left(1+i_{i}^{*}\right)} \frac{d i_{i}^{*}}{d \theta_{t}}$, respectively. The analogous elasticity equations for the changes in $\Omega_{t}^{*}$ and $\theta_{t}^{*}$ can be derived in the similar way.

Equations (43)-(48) show that the quantity of each currency used in international trade financing depends upon the liquidity in the market for bonds denominated in that currency, which is reflected by the interest rate on those bonds. Hence, $\hat{e}_{t}$ depends on the relative liquidity of the two markets for bonds denominated in the home currency and the foreign 
currency, respectively. How $P_{1 t} c_{1 t}^{*}$ and $P_{2 t}^{*} c_{2 t}$ are affected by the economic disturbances is determined by the elasticities of the changes in $\left(1+i_{t}\right)$ and $\left(1+i_{t}^{*}\right)$ with respect to the changes in the realizations of those exogenous random variables. The following discussion will show that

1. A monetary injection by way of an open market purchase, $\bar{y}_{t}$, has only a "pure liquidity effect" such that $\frac{d i_{1}}{d y_{t}}<0, \forall \sigma$.

2. A monetary injection in the form of a lump-sum transfer, $x_{t}$, has a liquidity effect and an expected price effect. These two effects operate in opposite directions. However, it can be shown that the liquidity effect dominates and $\frac{d i_{i}}{d x_{t}}<0, \forall \sigma$.

3. The elasticity of the changes in $\left(1+i_{t}\right)$ with respect to the changes in the home country's productivity shock, $\theta_{t}$, is determined by the elasticity of the changes in $p_{1 t}$ with respect to. the changes in $\theta_{t} \cdot \frac{\theta_{t}}{\left(1+i_{t}\right)} \frac{d i_{t}}{d \theta_{t}}=1+\frac{\theta_{1}}{p_{1 t}} \frac{d p_{1}}{d \theta_{t}}$ and $\operatorname{sign}\left[1+\frac{\theta_{1}}{p_{1 t}} \frac{d p_{1}}{d \theta_{t}}\right]=\operatorname{sign}(1-\sigma)$, where $\sigma$ is the constant elasticity of substitution between the consumption of the two goods.

4. How the economic disturbances of the home economy affect $i^{*}$ depends critically upon the value of $\sigma . \operatorname{sign} \frac{d i_{i}^{*}}{d y_{t}}=\operatorname{sign} \frac{d i_{i}^{*}}{d x_{t}}=\operatorname{sign} \frac{d i_{i}^{*}}{d \theta_{t}}=\operatorname{sign}(\sigma-1)$.

The illustration of these results is in Section 4.

As mentioned before, the beginning-of-period exchange rate, after the current state of the world is known, $\hat{e}_{t}$, is in general different from the end-of-period exchange rate, $e_{t}$. The only case where they are equal is if the two nominal interest rates are identical. Thus, the exchange rate may fluctuate both within a period and across periods. However, once $e_{t}, i_{t}$ and $i_{t}^{*}$ are determined, $\hat{e}_{t}$ will be pinned down 'by equation (17'). So the following discussion of the exchange rate will focus on the end-of-period exchange rate, $e_{t}$.

As shown in equation (40), the exchange rate (end-of-period), $e_{t}$, depends upon the relative size of the flows of the two countries' currencies to the foreign exchange market 
at the end of the period. This is determined by two factors. The first is the interest rate ratio $\left(1+i_{t}\right) /\left(1+i_{t}^{*}\right)$. The second is the relative quantities of the two countries' currencies used in international trade financing, $\left(P_{1 t} c_{1 t}^{*}\right) /\left(P_{2 t}^{*} c_{2 t}\right)$. Both of these two factors reflect the relative liquidity of the home currency-denominated bond market and the foreign currencydenominated bond market. If the market for home currency-denominated bonds is relatively more liquid, $\left(1+i_{t}\right) /\left(1+i_{t}^{*}\right)$ is less than one, and the quantity of home currency used in international trade financing, $P_{1 t} c_{1 t}^{*}$, is smaller than the quantity of foreign currency used in international trade financing, $P_{2 t}^{*} c_{2 t}$, then the home currency will appreciate.

The special feature of this model is the dependence of the exchange rates on the relative liquidity of the home currency-denominated bond market and the foreign currencydenominated bond market. This special feature is absent in other models, for example, Stockman(1980), Lucas (1982), and Svensson (1985). They simply have the purchasingpower-parity law of exchange rate determination which does not capture the liquidity effects.

\section{Solving for an Equilibrium}

Assume that there exists an equilibrium in which all of the cash-in-advance constraints for both countries are always binding, which implies $\mu_{j}(s)>0$ and $\mu_{j}^{*}(s)>0, \forall j=1,2,3,4$. In this equilibrium, $m_{h}(s)=m_{f}^{*}(s)=1, m_{f}(s)=m_{h}^{*}(s)=0, \forall s, n$ and $n^{*}$ are fixed numbers which are between zero and one. The representative home country household's necessary conditions (11)-(14) and the analogous necessary conditions of the foreign representative household imply

$$
\begin{aligned}
& E\left[\frac{1+i(s)}{1+x(s)}\right]=\frac{1}{\beta}, \\
& E\left[\frac{1+i^{*}(s)}{1+x^{*}(s)}\right]=\frac{1}{\beta^{*}},
\end{aligned}
$$




$$
\begin{array}{rlr}
c_{j}\left(p_{1}(s), p_{2}(s)\right) & =\frac{(1-n) p_{j}(s)^{-\sigma}}{\left[p_{1}(s)^{1-\sigma}+p_{2}(s)^{1-\sigma}\right]}, & j=1,2, \\
c_{j}^{*}\left(p_{1}^{*}(s), p_{2}^{*}(s)\right) & =\frac{\left(1-n^{*}\right) p_{j}^{*}(s)^{-\sigma}}{\left[p_{1}^{*}(s)^{1-\sigma}+p_{2}^{*}(s)^{1-\sigma}\right]}, & j=1,2, \\
w(s) & =\frac{p_{1}(s) \theta(s)}{1+i(s)}=\frac{1}{\beta}[1+x(s)](1-n), \\
w^{*}(s) & =\frac{p_{2}^{*}(s) \theta^{*}(s)}{1+i^{*}(s)}=\frac{1}{\beta^{*}}\left[1+x^{*}(s)\right]\left(1-n^{*}\right), \\
q(s) & =\frac{1}{1+i(s)}=\frac{[1+x(s)](1-n)}{\beta \theta(s) p_{1}(s)}, \\
q^{*}(s) & =\frac{1}{1+i^{*}(s)}=\frac{\left[1+x^{*}(s)\right]\left(1-n^{*}\right)}{\beta^{*} \theta^{*}(s) p_{2}^{*}(s)} .
\end{array}
$$

Expressions (53)-(56) show that open market purchases, $y$ and $y^{*}$, do not change the wage rates and they affect the bond prices only through their effects on $p_{1}$ and $p_{2}^{*}$. As pointed out in Lucas (1990), this kind of open market purchase only has a "pure liquidity effect" and the inflationary effect has been isolated.

Substitute the expressions (51)-(56), equations (20)-(23), (30) and (33)-(38) into equations (28), (29) and (40), we have a simultaneous equation system of three equations, (57)(59), in three unknowns, $p_{1}, p_{2}^{*}$ and $e$.

$$
\begin{aligned}
& {\left[\frac{\theta^{*} \beta^{*} v^{*}}{1+x^{*}}\right] \text { e } \delta p_{2}^{* 2} c_{2}\left(p_{1}, \frac{p_{2}^{* 2} e \delta \theta^{*} \beta^{*} v^{*}}{1+x^{*}}\right)=\left[\frac{\theta \beta v}{1+x}\right] p_{1}^{2} c_{1}^{*}\left(\frac{p_{1}^{2} \theta \beta v}{(1+x) e \delta}, p_{2}^{*}\right)} \\
& n+x+y=\frac{1+x}{\theta \beta v}\left[c_{1}\left(p_{1}, \frac{p_{2}^{* 2} e \delta \theta^{*} \beta^{*} v^{*}}{1+x^{*}}\right)+c_{1}^{*}\left(\frac{p_{1}^{2} \theta \beta v}{(1+x) e \delta}, p_{2}^{*}\right)\right]+p_{1} c_{1}^{*}\left(\frac{p_{1}^{2} \theta \beta v}{(1+x) e \delta}, p_{2}^{*}\right), \\
& n^{*}+x^{*}+y^{*}=\frac{1+x^{*}}{\theta^{*} \beta^{*} v^{*}}\left[c_{2}\left(p_{1}, \frac{p_{2}^{* 2} e \delta \theta^{*} \beta^{*} v^{*}}{1+x^{*}}\right)+c_{2}^{*}\left(\frac{p_{1}^{2} \theta \beta v}{(1+x) e \delta}, p_{2}^{*}\right)\right]+p_{2}^{*} c_{2}\left(p_{1}, \frac{p_{2}^{* 2} e \delta \theta^{*} \beta^{*} v^{*}}{1+x^{*}}\right),
\end{aligned}
$$


where $v \equiv \frac{1}{1-n}, \quad v^{*} \equiv \frac{1}{1-n^{*}}, \quad p_{1}^{*}=\frac{p_{1}^{2} \theta \beta v}{(1+x) e \delta} \quad$ and $\quad p_{2}=\frac{p_{2}^{* 2} e \delta \theta^{*} \beta^{*} v^{*}}{1+x^{*}}$

The equilibrium prices, $p_{1}$ and $p_{2}^{*}$, and the exchange rate, $e$, can then be expressed as functions of $s, n$ and $n^{*}$ only. Given the distribution function $G(s)$, the equilibrium values of $n$ and $n^{*}$ can be solved by substituting the expressions (55) and (56), and the three functions, $p_{1}\left(s, n, n^{*}\right), p_{2}^{*}\left(s, n, n^{*}\right)$ and $e\left(s, n, n^{*}\right)$, into equations (49) and (50).

There is a continuum of equilibria which have the common set of equilibrium values of

$$
\begin{aligned}
& \left\{n, p(s), \gamma(s), y(s), c_{1}(s), c_{2}(s), l(s), b(s), z(s),\right. \\
& \left.n^{*}, p^{*}(s), \gamma^{*}(s), y^{*}(s), c_{1}^{*}(s), c_{2}^{*}(s), l^{*}(s), b^{*}(s), z^{*}(s)\right\} .
\end{aligned}
$$

Each of these equilibria is characterized by a distinct vector of equilibrium values,

$$
\left[b_{h}(s), b_{f}(s), z_{h}(s), z_{f}(s), b_{h}^{*}(s), b_{f}^{*}(s), z_{h}^{*}(s), z_{f}^{*}(s)\right],
$$

which satisfies equations (28)-(31) and (35)-(38). In spite of having eight equations in these eight unknowns, there are only seven independent equations. Consequently, the equilibrium values of these eight decision variables are indeterminate. This indeterminacy arises because what really matters are the ultimate allocations of currency across the borrowers: $b, z, b^{*}$ and $z^{*}$, but not the ways to finance them. In equilibrium, the effective costs of financing by issuing bonds denominated in either currency are equalized.

All of these equilibria are actually equivalent as they have identical real allocation and pricing rules. For simplifying the discussion of the effects and the transmission mechanism for economic fluctuations in the following section, the particular equilibrium in which $b_{h}=b$, $z_{f}=z, b_{f}^{*}=b^{*}, z_{h}^{*}=z^{*}$ and $b_{f}=z_{h}=b_{h}^{*}=z_{f}^{*}=0$ will be chosen to illustrate the results of the comparative statics exercises. In this particular equilibrium, there is no need for the foreign exchange market to be opened at the beginning of the period, after the current state of the world is revealed, because there are no market participants. 


\section{Comparative Static Analysis}

Some comparative statics exercises will now be performed to analyze the impacts of the monetary shocks and real disturbances on the world equilibrium. ${ }^{16}$ Given the distribution function $G, n$ and $n^{*}$ are independent of the realization of 8 . By totally differentiating the simultaneous equation system, equations (57)-(59), we can derive the effects of these disturbances on the equilibrium values of the exchange rate, $e$, the price of good 1 in units of home currency, $p_{1}$, and the price of good 2 in units of foreign currency, $p_{2}^{*}$. The effects on other macroeconomic aggregates can then be calculated. The details of these comparative statics exercises are presented in Appendix 2. Tables 1-3 summarize the results of these exercises, which show that the effects depend critically on the value of the constant elasticity of substitution in consumption, $\sigma$, between the two goods. ${ }^{17}$ The directions of the responses of $e, p_{1}$, and $p_{2}^{*}$ are unambiguous except in the case of monetary injections through lumpsum transfers. In that case, the changes in $e$ and $p_{1}$ are ambiguous. The reasons for the ambiguity will be illustrated below.

\section{Open Market Purchases}

Consider a larger realization of the monetary injection by way of an open market purchase, $\bar{Y}$. As this monetary injection is through the home financial intermediaries, the first impact of this monetary shock is a decrease in the interest rate on the home currency-denominated bonds, $i$. Because this monetary injection is temporary, it does not affect the wage rate of the home country workers. Given the fixed wage rate and the decrease in the cost of financing, firms are able to reduce the home price of good 1 . If other variables remain unchanged, the initial decrease in $p_{1}$ will raise the relative prices of good $2, p_{2} / p_{1}$ and $p_{2}^{*} / p_{1}^{*}$. Therefore, for $\sigma>1, \sigma=1$ and $0 \leq \sigma<1$, the expenditure share of good 2 in each

\footnotetext{
${ }^{16}$ Though all of the economic disturbances are determined by the realisation of the current state of the world, these comparative statics exercises are performed by allowing only one of these exogenous variables to vary while assuming the rest being constant.

${ }^{17}$ The utility function is Cobb-Douglas if $\sigma=1$. The two goods are gross substitutes if $\sigma>1$. They are gross complements if $0 \leq \sigma<1$.
} 
shopper's budget becomes smaller, constant and larger, respectively. This, in turn, changes the demand for currency of the importers in the loans market, and also changes their demand for currency in the foreign exchange market at the end of the period. Equation (40) states that $e$ is determined by the ratio of the expenditure shares of the imported goods in the two shoppers' budget constraints, $\left(P_{2} c_{2}\right) /\left(P_{1}^{*} c_{1}^{*}\right)$. Thus $e$ is expected to fall, be unaffected and rise in the cases of $\sigma>1, \sigma=1$ and $0 \leq \sigma<1$, respectively. The expected movement of the exchange rate induces further adjustment in the world economy. The home importer raises (reduces) his ultimate demand for foreign currency, $z$, if he expects $e$ to fall (rise). With a fixed supply of foreign currency in the financial market, the interest rate $i^{*}$ will adjust to clear the market. Liquidity in the foreign currency-denominated bond market is reallocated from the foreign firm (home importer) to the home importer (foreign firm). Hence, in addition to the impacts on the home economy, the effects of this monetary shock are transmitted to the foreign economy. The interest rate $i^{*}$ and the foreign price of good $2, p_{2}^{*}$, rise (fall), while the foreign employment level, $l^{*}$, and foreign output, $Q^{*}$, fall (rise). Only in the case of $\sigma=1$, the foreign economy is insulated from the shocks of the home country.

The correlations of output fluctuations across countries depend highly on the substitutability of the two consumption goods in the consumers' preferences. The lower the substitutability of the two goods is, the higher the (positive) correlations of output across countries will be. However, the cross-country consumption correlations are determined by how close the comovements of the goods prices in the two economies are. Equations (33) and (34) state that the difference between the price of a good in the importing country and the price of the same good in the exporting country is determined by the cost of financing and the exchange rate. An economic disturbance will affect liquidity in the financial markets, reflected in the fluctuations in the nominal interest rates and the exchange rate. Because of the presence of the cash-in-advance constraints, both the relative prices and the nominal prices of the two goods faced by the two representative shoppers are affected by the economic disturbances 
differently. Hence, the consumption of the two households will adjust differently, and result in low correlations in consumption across countries.

As shown in Table 1, the effects on the two representative households' consumption of good 2, $c_{2}$ and $c_{2}^{*}$, depend on the value of $\sigma$. If $\sigma>1, c_{2}$ rises while $c_{2}^{*}$ falls. If $\sigma=1, c_{2}$ and $c_{2}^{*}$ are not affected by this monetary injection. If $0 \leq \sigma<1, c_{2}$ falls while $c_{2}^{*}$ rises. In addition, for any value of $\sigma$, the consumption of good 1 by the foreign representative household, $c_{1}^{*}$, increases. However, the changes in the home representative household's consumption of good $1, c_{1}$, are ambiguous. Because of the ambiguity of the changes in $c_{1}$, the effects on the home country's employment level, $l$, and output, $Q$, are also ambiguous. There are three effects on $c_{1}$. They are a substitution effect caused by changes in $p_{2} / p_{1}$ and two income effects induced by changes in $p_{1}$ and $p_{2}$, respectively. If $c_{1}$ increases, $l$ will also increase. ${ }^{18}$

If $\sigma>1$, the effect of $e$ dominates the effect of $p_{2}^{*}$ on $p_{2}$, so that $p_{2}$ falls, which results in an ambiguous effect on $p_{2} / p_{1}$. If $p_{2} / p_{1}$ increases, the substitution effect caused by the increase in $p_{2} / p_{1}$ and the income effects respectively caused by the decreases in $p_{1}$ and $p_{2}$ will act in the same direction and raise $c_{1}$. This, in turn, implies an increase in the output (employment) of the home country. If $p_{2} / p_{1}$ decreases, the substitution effect will reduce $c_{1}$. However, it is expected that the substitution effect will be dominated by the income effects, so $c_{1}$ and the home country's output are expected to rise. Thus if the two consumption goods are gross substitutes $(\sigma>1)$, the national output movements of the two countries are negatively correlated. The home country's output (employment) rises, while the foreign country's output (employment) falls. The movements of the nominal interest rates are also negatively correlated. The interest rate on the home currency-denominated bonds falls, while the interest rate on the foreign currency-denominated bonds rises. The exchange rate decreases, and the home currency appreciates.

If $\sigma=1, p_{2}$ is not affected by the monetary injection of the home economy. There are a

\footnotetext{
${ }^{18} \mathrm{~A}$ sufficient (but not necessary) condition for $\left(d c_{1} / d y\right)>0$ is $\left[\sigma+\pi_{12}^{*}\left(1-\pi_{12}^{*}\right)\right]>0$
} 
substitution effect induced by the increase in $p_{2} / p_{1}$ and an income effect induced by the fall in $p_{1}$. These imply an increase in $c_{1}$. The home country's output, $Q$, and the employment level, $l$, rise.

If $0 \leq \sigma<1$, the two goods are complements. The substitution effect induced by the increase in $p_{2} / p_{1}$, raises $c_{1}$. However, the income effects are ambiguous because $p_{1}$ decreases while $p_{2}$ increases. If the substitution effect dominates, $c_{1}$ and the home country's output will increases. Thus, in this case, the correlations of the interest rates and the national output (employment) movements are both positive. Both countries increase their real output and the interest rates, $i$ and $i^{*}$, both fall. The home currency depreciates.

When the value of $\sigma$ is sufficiently small, the substitution effect is weak. Since the expenditure share of $c_{2}$ in the home representative shopper's budget is large, the income effect of $p_{2}$ on $c_{1}$ may dominate, $c_{1}$ will fall, and the effect on $Q$ will be ambiguous. However, $Q$ can increase if the increase in $c_{1}^{*}$ is larger than the decrease in $c_{1}$. For the extreme case in which $\sigma=0$, the movements of the two countries' output are perfectly positively correlated, while the correlations of consumption are negatively correlated across countries. Both countries increase their output. The consumption of each good by the home representative household falls, but consumption of each good by the foreign representative household rises. Though this is an extreme case, it indicates that, when the complementarity of the two consumption goods is high and the goods prices move quite differently in the two economies, this model is able to generate output fluctuations across countries which are more highly positively correlated across countries than consumption fluctuations.

The effects of a larger realization of the monetary injection by way of an open market purchase can be summarized as follows. It can be shown that

$$
\frac{d p_{1}}{d y}<0, \quad \frac{d i}{d y}<0, \quad \frac{d\left(p_{2}^{*} / p_{1}^{*}\right)}{d y}>0, \quad \frac{d c_{1}^{*}}{d y}>0, \quad \forall \sigma,
$$




$$
\begin{aligned}
& \operatorname{sign} \frac{d e}{d y}=\operatorname{sign} \frac{d p_{2}}{d y}=\operatorname{sign} \frac{d l^{*}}{d y}=\operatorname{sign} \frac{d c_{2}^{*}}{d y}=\operatorname{sign} \operatorname{cov}\left(i, i^{*}\right)=\operatorname{sign}(1-\sigma), \\
& \operatorname{sign} \frac{d p_{2}^{*}}{d y}=\operatorname{sign} \frac{d i^{*}}{d y}=\operatorname{sign} \frac{d c_{2}}{d y}=\operatorname{sign}(\sigma-1), \\
& \frac{d\left(p_{2} / p_{1}\right)}{d y}>0, \quad \frac{d p_{1}^{*}}{d y}<0, \quad \forall \sigma \leq 1, \\
& \frac{d c_{1}}{d y}\left\{\begin{array}{lll}
>0 & \text { if } \sigma=1 \\
<0 & \begin{array}{l}
\text { if } \sigma=0 \\
\text { otherwise, }
\end{array}
\end{array}\right. \\
& \text { if } \frac{d l}{d y} \begin{cases}>0 & \text { if } \sigma=1 \\
>0 & \text { if } \sigma=0 \\
=? & \text { otherwise, }\end{cases} \\
& \text { then } \quad \begin{array}{lll}
\frac{d l}{d y}>0, & \forall \sigma & \text { and } \quad \operatorname{sign} \operatorname{cov}\left(l, l^{*}\right)=\operatorname{sign}(1-\sigma) .
\end{array}
\end{aligned}
$$

\section{Lump Sum Transfers}

The effects of a larger monetary injection to the representative home intermediary in the form of a lump-sum transfer, $X$, are not as clear as in the case of open market purchases. The comparative statics exercise shows that the direction of the movement of $p_{2}^{*}$ and $i^{*}$ are the same as with a larger volume of open market purchases. The movement of $p_{1}$ is ambiguous due to the two opposing forces, namely, an increase in the wage rate and a decrease in the opportunity cost of using cash to finance production in the home country. This permanent increase in the per capita stock of the home currency will increase the wage rate because workers request a higher wage rate for maintaining their purchasing power in next period. However, the monetary injection increases liquidity in the home currency-denominated bond market and lowers the market interest rate, $i$. This implies that the expected price effect is dominated by the liquidity effect, $\frac{d i}{d w}<0, \forall \sigma$. The change in the effective wage rate $w(1+i)$ is ambiguous and so is the change in $p_{1}$. Only in the case of $\sigma=1$, can it be shown that $p_{1}$ decreases. 
For the exchange rate, the movement is unambiguous in the cases of $0 \leq \sigma<1$ ( $e$ will rise) and of $\sigma=1$ ( $e$ will be unaffected). However, in the case of $\sigma>1, e$ will decrease (as that of open market purchases) only if $\pi_{11}^{*}$ is sufficiently small. This can be explained in the following way. Since the change in $p_{1}$ is ambiguous, the decrease in $i$ may only reduce $p_{1}^{*}$ marginally. The demand for good 1 by the foreign shoppers will increase. We have to restrict $\pi_{11}^{*}$ to be sufficiently small such that the demand for good 1 and the ultimate demand for home currency, $z^{*}$, will not increase too much. Otherwise, the interest rate will increase to offset part of the original reduction and thus put a upward pressure on $p_{1}$. Thus if $\pi_{11}^{*}$ is sufficiently small, a monetary injection through a lump-sum transfer can have similar effects on the national output and interest rate movements as with monetary injections in the form of open market purchases. Basically, the transmission mechanism of the effects of home country's lump-sum transfers of newly issued currency on the foreign economy is the same as that of open market purchases. Loosely speaking, a monetary injection in the form of a lump-sum transfer to intermediaries is more inflationary and less expansionary than a monetary injection in the form of open market purchases. This is because the wage rate of the home workers increases in the former case while it remains constant in the latter case.

\section{Productivity Shocks}

As the home country has a larger realization of the productivity parameter $\theta$, its workers become more productive, so that home firms are able to reduce the home price of good 1 . Both countries' relative prices of good 2, in units of good 1, rise. Therefore, this positive productivity shock in the home country will affect the world economy through the same mechanism as that of the open market purchases case [ see Table 2 ].

Unlike the impacts of monetary shocks, the output of the home economy increases unambiguously in this case. Moreover, the effects on the employment level $l$ and the interest rate $i$ are quite different from those of monetary shocks. The rise in productivity allows 
home firms to reduce $l$, which tends to reduce $i$, while the decrease in $p_{1}$ induces a larger demand for good 1, which increases $l$ and has an upward force on $i$. Consequently, the effects on $l$ are ambiguous, and the changes in $i$ are determined by the elasticity of the changes in $p_{1}$ with respect to the changes in $\theta,-\frac{\theta_{2}}{p_{10}} \frac{d p_{14}}{d \theta_{t}} \cdot \frac{\theta_{1}}{\left(1+i_{t}\right)} \frac{d i_{1}}{d \theta_{t}}=1+\frac{\theta_{2}}{p_{1 t}} \frac{d p_{11}}{d \theta_{t}}$ and sign $\left[1+\frac{\theta_{1}}{p_{1 i}} \frac{d p_{1}}{d \theta_{t}}\right]=\operatorname{sign}(1-\sigma)$. In the case of $\sigma>1$, the elasticity is larger than one. The effect of the decrease in $p_{1}$ dominates the effect of the increase in $\theta$ on $i$. As a result, $i$ decreases. In the case of $\sigma=1$, the elasticity is equal to one. The two forces of $\theta$ and $p_{1}$ on $i$ are entirely offset by each other, so that $i$ is unaffected by the productivity shock. In the case of $0<\sigma<1$, the elasticity is smaller than one. Thus the effect of $\theta$ dominates, and $i$ increases.

It can be shown that a productivity shock in the home economy has the following effects,

$$
\begin{aligned}
& \frac{d p_{1}}{d \theta}<0, \quad \frac{d\left(p_{2} / p_{1}\right)}{d \theta}>0, \quad \frac{d\left(p_{2}^{*} / p_{1}^{*}\right)}{d \theta}>0, \quad \frac{d c_{1}^{*}}{d \theta}>0, \quad \forall \sigma, \\
& \operatorname{sign} \frac{d e}{d \theta}=\operatorname{sign} \frac{d p_{2}}{d \theta}=\operatorname{sign} \frac{d i}{d \theta}=\operatorname{sign} \frac{d l^{*}}{d \theta}=\operatorname{sign} \frac{d c_{2}^{*}}{d \theta}=\operatorname{sign}(1-\sigma), \\
& \operatorname{sign} \frac{d p_{2}^{*}}{d \theta}=\operatorname{sign} \frac{d i^{*}}{d \theta}=\operatorname{sign} \frac{d c_{2}}{d \theta}=\operatorname{sign}(\sigma-1),
\end{aligned}
$$$$
\operatorname{sign} \operatorname{cov}\left(i, i^{*}\right) \begin{cases}=0 & \text { if } \sigma=1 \\ <0 & \text { otherwise, }\end{cases}
$$$$
\frac{d p_{1}^{*}}{d \theta}<0, \quad \forall \sigma \leq 1,
$$$$
\frac{d Q}{d \theta}>0, \quad \forall \sigma \geq 1 \text {, }
$$$$
\frac{d c_{1}}{d \theta} \begin{cases}>0 & \text { if } \sigma \geq 1 \\ <0 & \text { if } \sigma=0 \\ =? & \text { otherwise, }\end{cases}
$$

if $\frac{d c_{1}}{d \theta}>0$ for $0<\sigma<1$, then $\operatorname{sign} \operatorname{cov}\left(Q, Q^{*}\right)=\operatorname{sign}(1-\sigma)$,

where $Q \equiv c_{1}+c_{1}^{*}$ and $Q^{*} \equiv c_{2}+c_{2}^{*}$. 


\section{Conclusion}

In summary, both monetary shocks and real disturbances can generate fluctuations in exchange rates and interest rates, and result in comovements of economic variables of the two economies. An exchange rate equation, which incorporates liquidity effects, is derived in this model. Liquidity effects also act as the transmission mechanism for economic fluctuations. The correlations among the two economies' macroeconomic aggregates depend on the substitutability of the two consumption goods in consumers' preferences.

Svensson and van Wijnbergen (1989) analyze the international transmission of monetary policy shocks in an open economy disequilibrium model with sticky goods prices and excess capacity. Though they also have similar findings, which show that the effect of a home country's monetary expansion on foreign output depends on whether the two goods are complements or substitutes, the transmission mechanism of the effect is quite different from that in this model. ${ }^{19}$ In their model, output is demand determined. The home country's monetary expansion has real effects on the world economy as it depreciates the home currency and implies an expected inflation, which affects the demands for goods of the economic agents. In this model, the only rigidity is in the deposit decision, while all prices are flexible. This paper stresses the role of international financial markets in allocating liquidity across market participants in the two countries. Monetary injections induce a redistribution of liquidity in the financial markets. For different values of the constant elasticity of substitution between the two goods in consumers' preferences, the allocation of liquidity will be affected differently. Hence, real activity in the world economy will be affected differently, and different patterns of fluctuations in exchange rates, interest rates and goods prices will be generated.

With the imposed financial structure here, this model is able to generate higher output correlations and lower consumption correlations across countries, which may be an explana-

\footnotetext{
${ }^{19}$ Given the intertemporal elasticity of substitution in consumption is unity, our classifications of complements and substitutes are equivalent to the "Edgeworth-Pareto" complements and substitutes used in Svensson and van Wijnbergen (1989).
} 
tion (with monetary features) for the discrepancies between data and the predictions given by the usual open economy real business cycle models.

This paper develops a theoretical analysis of the role of liquidity effects in an open economy. To evaluate the model quantitatively would require introducing physical investment and international debt carried over periods. However, that would be a topic for future research. 
Figure 1: Timing of Information and Transactions of the Home Representative Household

\section{Period $t$}

- Beginning-of-period cash holdings, $M_{h t}$ and $M_{f t}$.

- Deposits $N_{t}$ units of home currency.

- The household separates.

* Shopper

* Importer

* Financial Intermediary

* Firm

* Worker

$$
M_{h t}-N_{t}
$$

$M_{f t}$

$N_{t}$

- Current state of the world, $s_{t}$, is revealed to everybody.

Monetary injections occur. Financial intermediary's cash holdings, $N_{t}+X_{t}+Y_{t}$.

- Markets are opened.

* Loans markets

* Foreign exchange market

* Labor markets

* Goods markets

- Markets are closed.

- Foreign exchange market is reopened.

- Loan repayments are made.

- The household is reunited, all remaining cash is pooled, and goods purchased by shopper are consumed.

- Lump-sum rebates of interest payments from the home government, $\Gamma_{t}$.

- End-of-period cash holdings, $M_{h t+1}$ and $M_{f t+1}$.

Period $t+1$ 
Table 1. The Effects of an Open Market Purchase

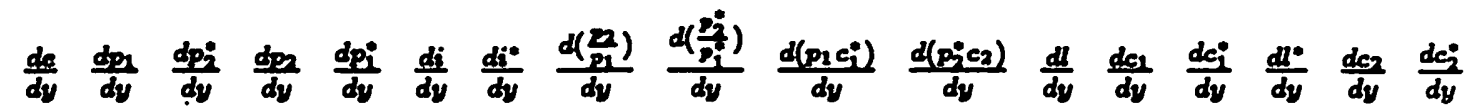

$$
\begin{aligned}
& \sigma>1-\ldots+\text { - } ?+\text { - } ?+?+-+ \\
& \sigma=10-00--0++t+0+t+000 \\
& 0<\sigma<1+--+---+++ \text { - }+ \text { ? + }-+ \\
& \sigma=0+--+---+++-+++
\end{aligned}
$$

Table 2. The Effects of a Productivity Shock

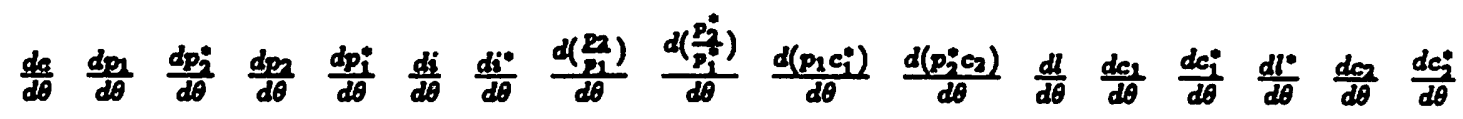

$$
\begin{aligned}
& \sigma>1-\text { - }- \text { ? }-+++ \text { ? }+ \text { ? + }++
\end{aligned}
$$

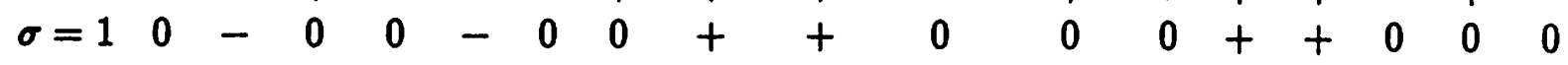

$$
\begin{aligned}
& 0<\sigma<1+--+-+-++?+?++-+ \\
& \sigma=0+--+-+-++?-?-++-+
\end{aligned}
$$

Table 3. The Effects of a Lump-sum Transfer

$$
\frac{d s}{d x} \frac{d p 1}{d x} \frac{d p_{2}^{*}}{d x} \frac{d i}{d x} \frac{d i^{*}}{d x}
$$

$$
\begin{array}{rrrrrr}
\sigma>1 & ? & ? & + & - & + \\
\sigma=1 & 0 & - & 0 & - & 0 \\
0 \leq \sigma<1 & + & ? & - & - & -
\end{array}
$$




\section{Appendix 1:}

\section{The Optimization Problem of the Foreign Representation Household}

The foreign representative household faces the following dynamic optimization problem. Given the distribution function $G$ and the collection of sequences

$$
\left\{\Lambda_{t}^{*}, \mathcal{P}_{t}^{*}, M_{t}, M_{t}^{*}, M_{h t}, M_{f t}, B_{f t}, Z_{f t}\right\}_{t=0}^{\infty} \text {, }
$$

the household chooses the collection of sequences

$$
\left\{N_{t}^{*}, c_{1 t}^{*}, c_{2 t}^{*}, Y_{t}^{*}, B_{h t}^{*}, Z_{h t}^{*}, B_{f t}^{*}, Z_{f t}^{*}, l_{t}^{*}, H_{t}^{*}, K_{h t}^{*}, K_{f t}^{*}\right\}_{t=0}^{\infty}
$$

to maximize the expected lifetime utility

$$
\begin{aligned}
E_{0}\left[\sum_{t=0}^{\infty} \beta^{* t} U\left(c_{1 t}^{*}, c_{2 t}^{*}, l_{t}^{*}\right)\right] & 0<\beta^{*}<1 \\
U\left(c_{1 t}^{*}, c_{2 t}^{*}, l_{t}^{*}\right)=\ln \left[c_{1 t}^{* \alpha}+c_{2 t}^{* \alpha}\right]^{\frac{1}{\alpha}}+\left[1-l_{t}^{*}\right] & \alpha \leq 1
\end{aligned}
$$

subject to

$$
\begin{aligned}
& M_{f t}^{*}-N_{t}^{*} \geq P_{1 t}^{*} c_{1 t}^{*}+P_{2 t}^{*} c_{2 t}^{*} \\
& N_{t}^{*}+X_{t}^{*}+Y_{t}^{*} \geq B_{f t}^{*}+Z_{f t}^{*}+B_{f t}+Z_{f t} \\
& B_{f t}^{*}+\frac{B_{h t}^{*}}{\hat{e}_{t}}-K_{f t}^{*}\left(\frac{1}{1+i_{t}^{*}}\right) \geq W_{t}^{*} H_{t}^{*} \\
& M_{h t}^{*}+Z_{h t}^{*}+Z_{f t}^{*} \hat{e}_{t}-K_{h t}^{*}\left(\frac{1}{1+i_{t}}\right) \geq P_{1 t} c_{1 t}^{*} \\
& \mathcal{F}^{*}\left(H_{t}^{*}\right)=\theta_{t}^{*} H_{t}^{*} \\
& M_{f t+1}^{*}=M_{f t}^{*}+X_{t}^{*}-Y_{t}^{*} i_{0 t}^{*}+P_{2 t}^{*} \mathcal{F}^{*}\left(H_{t}^{*}\right)-P_{2 t}^{*} c_{2 t}^{*}-W_{t}^{*} H_{t}^{*}+W_{t}^{*} l_{t}^{*}+\frac{B_{h t}^{*}}{\hat{e}_{t}}-Z_{f t}^{*} \\
&+\left(B_{f t}+Z_{f t}\right) i_{t}^{*}-\frac{\left(B_{h t}^{*}+Z_{h t}^{*}\right)\left(1+i_{t}\right)}{e_{t}}+K_{f t}^{*}\left(\frac{i_{t}^{*}}{1+i_{t}^{*}}\right)+\Gamma_{t}^{*} \\
& M_{h t+1}^{*}=M_{h t}^{*}+Z_{h t}^{*}+Z_{f t}^{*} \hat{e}_{t}+K_{h t}^{*}\left(\frac{i_{t}}{1+i_{t}}\right)-P_{1 t} c_{1 t}^{*}
\end{aligned}
$$


Define the value function corresponding to the foreign household's rescaled optimization problem $J^{*}(m, \delta, \tilde{s})$ by

$$
J^{*}(m, \delta, \tilde{s})=\max _{0 \leq n^{*} \leq m_{j}^{*}} \int_{c_{i}^{*}, c_{j}^{*}, V^{*}, b_{i}^{*}, x_{k^{*}, j_{j}^{*}, j_{j}^{*}, l^{*}, H^{*}, k_{i}^{*}, k_{j}^{*}}}\left\{U\left(c_{1}^{*}, c_{2}^{*}, l^{*}\right)+\beta^{*} J^{*}\left(m^{\prime}, \delta^{\prime}, s\right)\right\} d G(s)
$$

subject to

$$
\begin{aligned}
& m_{f}^{*}-n^{*} \geq p_{1}^{*} c_{1}^{*}+p_{2}^{*} c_{2}^{*} \\
& n^{*}+x^{*}+y^{*} \geq b_{f}^{*}+z_{f}^{*}+b_{f}+z_{f} \\
& b_{f}^{*}+\frac{b_{h}^{*}}{\hat{e} \delta}-k_{f}^{*}\left(\frac{1}{1+i^{*}}\right) \geq w^{*} H^{*} \\
& m_{h}^{*}+z_{h}^{*}+z_{f}^{*} \hat{e} \delta-k_{h}^{*}\left(\frac{i}{1+i}\right) \geq p_{1} c_{1}^{*} \\
& m_{f}^{* *}=\frac{1}{1+x^{*}}\left[m_{f}^{*}+x^{*}-y^{*} i_{0}^{*}+p_{2}^{*} \mathcal{F}^{*}\left(H^{*}\right)-p_{2}^{*} c_{2}^{*}-w^{*} H^{*}+w^{*} l^{*}+\frac{b_{h}^{*}}{\hat{e} \delta}-z_{f}^{*}\right. \\
&\left.+\left(b_{f}+z_{f}\right) i^{*}-\frac{\left(b_{h}^{*}+z_{h}^{*}\right)(1+i)}{e \delta}+k_{f}^{*}\left(\frac{i^{*}}{1+i_{1}^{*}}\right)+\gamma^{*}\right] \\
& m_{h}^{\prime *}=\frac{1}{1+x}\left[m_{h}^{*}+z_{h}^{*}+z_{f}^{*} e \delta+k_{h}^{*}\left(\frac{i}{1+i}\right)-p_{1} c_{1}^{*}\right]
\end{aligned}
$$




\section{Appendix 2 : Results of the Comparative Static Analysis}

By totally differentiating equations (57)-(59), we have

$$
\left[\begin{array}{llllll}
a_{11} & a_{12} & a_{13} & a_{14} & a_{15} & a_{16} \\
a_{21} & a_{22} & a_{23} & a_{24} & a_{25} & a_{28} \\
a_{31} & a_{32} & a_{33} & a_{34} & a_{35} & a_{36}
\end{array}\right]\left[\begin{array}{c}
d e \\
d p_{1} \\
d p_{2}^{*} \\
d x \\
d y \\
d \theta
\end{array}\right]=\left[\begin{array}{l}
0 \\
0 \\
0
\end{array}\right]
$$

where

$$
\begin{array}{ll}
a_{11}=-\frac{1}{e}\left[\pi_{22}+\pi_{11}^{*}-1\right] & a_{14}=-\frac{1}{1+z}\left[\pi_{11}^{*}-1\right] \\
a_{21}=\frac{1}{e}\left[\frac{w}{\theta}\left(c_{1} \pi_{12}+c_{1}^{*} \pi_{11}^{*}\right)+z^{*} \pi_{11}^{*}\right] & a_{24}=-\frac{1}{1+z}\left\{1+x-\left[\frac{w}{\theta}\left[c_{1}+c_{1}^{*}\left(\pi_{11}^{*}+1\right)\right]+z^{*} \pi_{11}^{*}\right]\right\} \\
a_{31}=-\frac{1}{e}\left[\frac{w^{*}}{\theta^{*}}\left(c_{2} \pi_{22}+c_{2}^{*} \pi_{21}^{*}\right)+z \pi_{22}\right] & a_{34}=-\frac{1}{1+z}\left[\frac{w^{*}}{\theta^{*}} c_{2}^{*} \pi_{21}^{*}\right] \\
a_{12}=\frac{1}{p_{1}}\left[\pi_{21}+2\left(\pi_{11}^{*}-1\right)\right] & a_{16}=0 \\
a_{22}=-\frac{1}{p_{1}}\left[\frac{w}{\theta}\left(c_{1} \pi_{11}+2 c_{1}^{*} \pi_{11}^{*}\right)+z^{*}\left(2 \pi_{11}^{*}-1\right)\right] & a_{25}=-1 \\
a_{32}=\frac{1}{p_{1}}\left[\frac{w^{*}}{\theta^{*}}\left(c_{2} \pi_{21}+2 c_{2}^{*} \pi_{21}^{*}\right)+z \pi_{21}\right] & a_{35}=0 \\
a_{13}=-\frac{1}{p_{2}^{*}}\left[2\left(\pi_{22}-1\right)+\pi_{12}^{*}\right] & a_{16}=\frac{1}{\theta}\left[\pi_{11}^{*}-1\right] \\
a_{23}=\frac{1}{p_{2}^{*}}\left[\frac{w}{\theta}\left(2 c_{1} \pi_{12}+c_{1}^{*} \pi_{12}^{*}\right)+z^{*} \pi_{12}^{*}\right] & a_{26}=-\frac{1}{\theta}\left[\frac{w}{\theta}\left[c_{1}+c_{1}^{*}\left(\pi_{11}^{*}+1\right)\right]+z^{*} \pi_{11}^{*}\right] \\
a_{33}=-\frac{1}{p_{2}^{*}}\left[\frac{w^{*}}{\theta^{*}}\left(2 c_{2} \pi_{22}+c_{2}^{*} \pi_{22}^{*}\right)+z\left(2 \pi_{22}-1\right)\right] & a_{36}=\frac{1}{\theta}\left[\frac{w^{*}}{\theta^{*}} c_{2}^{*} \pi_{21}^{*}\right] \\
\pi_{i i} \equiv-\frac{\partial c_{i} p_{i}}{\partial p_{i}}, & \pi_{i j} \equiv \frac{\partial c_{i}}{\partial p_{j}} \frac{p_{j}}{c_{i}}, \quad i, j=1,2, \quad i \neq j .
\end{array}
$$

Define

$$
\frac{1}{\left(e p_{1} p_{2}^{*}\right)} \frac{1}{A} \equiv\left|\begin{array}{lll}
a_{11} & a_{12} & a_{13} \\
a_{21} & a_{22} & a_{23} \\
a_{31} & a_{32} & a_{33}
\end{array}\right| .
$$


This derivation is for a general case. Now, we consider the CES utility function with the form

$$
\begin{aligned}
& U\left(c_{1}, c_{2}\right)=\ln \left[c_{1}^{\alpha}+c_{2}^{\alpha}\right]^{\frac{1}{\alpha}}, \quad \sigma \equiv \frac{1}{1-\alpha}, \quad \alpha \leq 1, \\
& \pi_{i i}=\left[\sigma+\frac{(1-\sigma) p_{i}^{1-\sigma}}{p_{1}^{1-\sigma}+p_{2}^{1-\sigma}}\right]>0, \\
& \pi_{i j}=-\left[\frac{(1-\sigma) p_{j}{ }^{1-\sigma}}{p_{1}{ }^{1-\sigma}+p_{2}{ }^{1-\sigma}}\right], \quad \operatorname{sign}\left(\pi_{i j}\right)=\operatorname{sign}(\sigma-1), \\
& \sigma>1 \quad \Rightarrow \quad 1<\pi_{i i}<\sigma, \quad 0<\pi_{i j}<\sigma-1, \\
& \sigma=1 \quad \Rightarrow \quad \pi_{i i}=1, \quad \pi_{i j}=0 \text {, } \\
& 0 \leq \sigma<1 \quad \Rightarrow \quad \sigma<\pi_{i i}<1, \quad \sigma-1<\pi_{i j}<0, \\
& \begin{array}{lr}
\pi_{i i}+\pi_{j j}=\sigma+1, & \pi_{i i}=1+\pi_{i j}, \\
\pi_{i j}+\pi_{j i}=\sigma-1, & \pi_{i i}+\pi_{j i}=\sigma, \\
\pi_{22}+\pi_{11}^{*}-1=\pi_{21}+\pi_{11}^{*}=\pi_{22}+\pi_{12}^{*}>\sigma .
\end{array}
\end{aligned}
$$

By using these properties, it can be shown that

$$
\begin{aligned}
& \frac{1}{A}=--\left\{\frac{w^{*}}{\theta^{*}} c_{2}\left[\left(\frac{w}{\theta} c_{1}+z^{*}\right) \pi_{22}+\frac{w}{\theta} c_{1}^{*}\left(1+\pi_{22}\right)\right]\left(1+\pi_{11}^{*}\right)\right. \\
&\left.+\left(\frac{w^{*}}{\theta^{*}} c_{2}^{*}+z\right)\left[\left(\frac{w}{\theta} c_{1}+z^{*}\right)\left(\pi_{22}+\pi_{12}^{*}\right)+\frac{w}{\theta} c_{1}^{*} \pi_{11}^{*}\left(1+\pi_{22}\right)\right]\right\}, \\
& A<0, \quad \forall \sigma \in[0, \infty) .
\end{aligned}
$$


Open Market Purchases (y)

$$
\begin{aligned}
& \frac{y}{e} \frac{d e}{d y}=A y\left[\frac{w^{*}}{\theta^{*}} c_{2}\left[2 \pi_{21}+\pi_{12}^{*}\left(3 \pi_{22}+1\right)\right]+\left(\frac{w^{*}}{\theta^{*}} c_{2}^{*}+z\right)\left(\pi_{21}+2 \pi_{12}^{*}\right)\right] \\
& \frac{y}{p_{1}} \frac{d p_{1}}{d y}=\frac{y}{(1+i)} \frac{d i}{d y}=A y\left[\frac{w^{*}}{\theta^{*}} c_{2} \pi_{22}\left(\pi_{11}^{*}+1\right)+\left(\frac{w^{*}}{\theta^{*}} c_{2}^{*}+z\right)\left(\pi_{22}+\pi_{12}^{*}\right)\right] \\
& \frac{y}{p_{2}^{*}} \frac{d p_{2}^{*}}{d y}=\frac{y}{\left(1+i^{*}\right)} \frac{d i^{*}}{d y}=-A y \frac{w^{*}}{\theta^{*}} c_{2}\left(\pi_{22}+1\right) \pi_{12}^{*} \\
& \frac{y}{p_{2}} \frac{d p_{2}}{d y}=\frac{y}{p_{2}^{*}} \frac{d p_{2}^{*}}{d y}+\frac{y}{\left(1+i^{*}\right)} \frac{d i^{*}}{d y}+\frac{y}{e} \frac{d e}{d y} \\
& =A y\left[\frac{w^{*}}{\theta^{*}} c_{2} \pi_{21}\left(\pi_{11}^{*}+1\right)+\left(\frac{w^{*}}{\theta^{*}} c_{2}^{*}+z\right)\left(2 \pi_{12}^{*}+\pi_{21}\right)\right] \\
& \frac{y}{p_{1}^{*}} \frac{d p_{1}^{*}}{d y}=\frac{y}{p_{1}} \frac{d p_{1}}{d y}+\frac{y}{(1+i)} \frac{d i}{d y}-\frac{y}{e} \frac{d e}{d y} \\
& =A y\left[\frac{w^{*}}{\theta^{*}} c_{2}\left(3-\pi_{11}^{*}\right)+\frac{w^{*}}{\theta^{*}} c_{2}^{*}+z\right]\left(\pi_{22}+1\right) \\
& \frac{y}{\left(\frac{p_{2}}{p_{1}}\right)} \frac{d\left(\frac{p_{2}}{p_{1}}\right)}{d y}=\frac{y}{p_{2}} \frac{d p_{2}}{d y}-\frac{y}{p_{1}} \frac{d p_{1}}{d y}=-A y\left[\frac{w^{*}}{\theta^{*}} c_{2}\left(\pi_{11}^{*}+1\right)+\left(\frac{w^{*}}{\theta^{*}} c_{2}^{*}+z\right)\left(2-\pi_{11}^{*}\right)\right] \\
& \frac{y}{\left(\frac{p_{2}^{*}}{p_{1}^{*}}\right)} \frac{d\left(\frac{p_{i}^{*}}{p_{1}^{*}}\right)}{d y}=\frac{y}{p_{2}^{*}} \frac{d p_{2}^{*}}{d y}-\frac{y}{p_{1}^{*}} \frac{d p_{1}^{*}}{d y}=-A y\left[2 \frac{w^{*}}{\theta^{*}} c_{2}+\frac{w^{*}}{\theta^{*}} c_{2}^{*}+z\right]\left(\pi_{22}+1\right) \\
& \frac{y}{p_{1} c_{1}} \frac{d\left(p_{1} c_{1}\right)}{d y}=\pi_{12}\left[\frac{y}{p_{2}} \frac{d p_{2}}{d y}-\frac{y}{p_{1}} \frac{d p_{1}}{d y}\right] \\
& \frac{y}{p_{2} c_{2}} \frac{d\left(p_{2} c_{2}\right)}{d y}=-\pi_{21}\left[\frac{y}{p_{2}} \frac{d p_{2}}{d y}-\frac{y}{p_{1}} \frac{d p_{1}}{d y}\right] \\
& \frac{y}{p_{1}^{*} c_{1}^{*}} \frac{d\left(p_{1}^{*} c_{1}^{*}\right)}{d y}=\pi_{12}^{*}\left[\frac{y}{p_{2}^{*}} \frac{d p_{2}^{*}}{d y}-\frac{y}{p_{1}^{*}} \frac{d p_{1}^{*}}{d y}\right] \\
& \frac{y}{p_{2}^{*} c_{2}^{*}} \frac{d\left(p_{2}^{*} c_{2}^{*}\right)}{d y}=-\pi_{21}^{*}\left[\frac{y}{p_{2}^{*}} \frac{d p_{2}^{*}}{d y}-\frac{y}{p_{1}^{*}} \frac{d p_{1}^{*}}{d y}\right] \\
& \frac{y}{p_{1} c_{1}^{*}} \frac{d\left(p_{1} c_{1}^{*}\right)}{d y}=\frac{y}{p_{1}^{*} c_{1}^{*}} \frac{d\left(p_{1}^{*} c_{1}^{*}\right)}{d y}-\frac{y}{(1+i)} \frac{d i}{d y}+\frac{y}{e} \frac{d e}{d y} \\
& =-A y\left[\frac{w^{*}}{\theta^{*}} c_{2}\left(\pi_{11}^{*}+1\right)+\left(\frac{w^{*}}{\theta^{*}} c_{2}^{*}+z\right)\left(1+\pi_{12}^{*} \pi_{22}\right)\right] \\
& \frac{y}{p_{2}^{*} c_{2}} \frac{d\left(p_{2}^{*} c_{2}\right)}{d y}=\frac{y}{p_{2} c_{2}} \frac{d\left(p_{2} c_{2}\right)}{d y}-\frac{y}{\left(1+i^{*}\right)} \frac{d i^{*}}{d y}-\frac{y}{e} \frac{d e}{d y} \\
& =-A y\left[\frac{w^{*}}{\theta^{*}} c_{2}+\frac{w^{*}}{\theta^{*}} c_{2}^{*}+z\right]\left(\pi_{22}+1\right) \pi_{12}^{*}
\end{aligned}
$$




$$
\begin{aligned}
\frac{d l^{*}}{d y} & =-\frac{1}{w^{*}} \frac{d\left(p_{2}^{*} c_{2}\right)}{d y} \\
\frac{y}{c_{2}} \frac{d c_{2}}{d y} & =\frac{y}{p_{2} c_{2}} \frac{d\left(p_{2} c_{2}\right)}{d y}-\frac{y}{p_{2}} \frac{d p_{2}}{d y}=-A y\left[\frac{w^{*}}{\theta^{*}} c_{2}^{*}+z\right]\left(\pi_{22}+1\right) \pi_{12}^{*} \\
\frac{y}{c_{2}^{*}} \frac{d c_{2}^{*}}{d y} & =\frac{y}{p_{2}^{*} c_{2}^{*}} \frac{d\left(p_{2}^{*} c_{2}^{*}\right)}{d y}-\frac{y}{p_{2}^{*}} \frac{d p_{2}^{*}}{d y} \\
& =A y\left[\frac{w^{*}}{\theta^{*}} c_{2}\left(2 \pi_{21}^{*}+\pi_{12}^{*}\right)+\left(\frac{w^{*}}{\theta^{*}} c_{2}^{*}+z\right) \pi_{21}^{*}\right]\left(\pi_{22}+1\right) \\
\frac{y}{c_{1}} \frac{d c_{1}}{d y} & =\frac{y}{p_{1} c_{1}} \frac{d\left(p_{1} c_{1}\right)}{d y}-\frac{y}{p_{1}} \frac{d p_{1}}{d y} \\
& =-A y\left[\frac{w^{*}}{\theta^{*}} c_{2}\left(\pi_{11}^{*}+1\right)\left(\pi_{11}+\pi_{21}\right)+\left(\frac{w^{*}}{\theta^{*}} c_{2}^{*}+z\right)\left(\pi_{22}+\pi_{12}^{*}+\pi_{12}\left(2-\pi_{11}^{*}\right)\right)\right] \\
& =-A y\left[\frac{w^{*}}{\theta^{*}} c_{2}\left(\pi_{11}^{*}+1\right) \sigma+\left(\frac{w^{*}}{\theta^{*}} c_{2}^{*}+z\right)\left(\sigma+\pi_{12}^{*}\left(1-\pi_{12}^{*}\right)\right)\right] \\
\frac{y}{c_{1}^{*}} \frac{d c_{1}^{*}}{d y} & =\frac{y}{p_{1}^{*} c_{1}^{*}} \frac{d\left(p_{1}^{*} c_{1}^{*}\right)}{d y}-\frac{y}{p_{1}^{*}} \frac{d p_{1}^{*}}{d y} \\
& =-A y\left[\frac{w^{*}}{\theta^{*}} c_{2}\left(\pi_{11}^{*}+1\right)+\left(\frac{w^{*}}{\theta^{*}} c_{2}^{*}+z\right) \pi_{11}\right]\left(\pi_{22}+1\right) \\
\frac{d l}{d y} & =\frac{1}{\theta}\left[\frac{d c_{1}}{d y}+\frac{d c_{1}^{*}}{d y}\right]
\end{aligned}
$$

Productivity Shocks ( $\theta$ )

$$
\begin{aligned}
\frac{\theta}{e} \frac{d e}{d \theta}= & A\left\{\frac{w^{*}}{\theta^{*}} c_{2}\left[\left(\frac{w}{\theta} c_{1}+z^{*}\right)\left(\pi_{12}^{*}\left(\pi_{22}+1\right)+2 \pi_{21}\right)+4 \frac{w}{\theta} c_{1}^{*}\left(\pi_{21}+\pi_{12}^{*}+\pi_{21} \pi_{12}^{*}\right)\right]\right. \\
& \left.+\left(\frac{w^{*}}{\theta^{*}} c_{2}^{*}+z\right)\left[\left(\frac{w}{\theta} c_{1}+z^{*}\right)\left(\pi_{21}+\pi_{12}^{*}\right)+\frac{w}{\theta} c_{1}^{*}\left(\pi_{12}^{*}\left(\pi_{22}+1\right)+2 \pi_{21}\right)\right]\right\} \\
\frac{\theta}{p_{1}} \frac{d p_{1}}{d \theta}= & A\left\{\frac{w^{*}}{\theta^{*}} c_{2}\left[\frac{w}{\theta} c_{1}+2 \frac{w}{\theta} c_{1}^{*}+z^{*}\right] \pi_{22}\left(\pi_{11}^{*}+1\right)\right. \\
& \left.+\left(\frac{w^{*}}{\theta^{*}} c_{2}^{*}+z\right)\left[\left(\frac{w}{\theta} c_{1}+z^{*}\right)\left(\pi_{22}+\pi_{12}^{*}\right)+\frac{w}{\theta} c_{1}^{*}\left(\pi_{11}^{*}\left(\pi_{22}+1\right)+\pi_{21}\right)\right]\right\} \\
\frac{\theta}{p_{2}^{*}} \frac{d p_{2}^{*}}{d \theta}= & \frac{\theta}{\left(1+i^{*}\right)} \frac{d i^{*}}{d \theta}=-A \frac{w^{*}}{\theta^{*}} c_{2}\left[\frac{w}{\theta} c_{1}+\frac{w}{\theta} c_{1}^{*}\left(\pi_{22}+1\right)+z^{*}\right] \pi_{12}^{*} \\
\frac{\theta}{(1+i)} \frac{d i}{d \theta}= & 1+\frac{\theta}{p_{1}} \frac{d p_{1}}{d \theta}=A \frac{w}{\theta} c_{1}^{*}\left[\frac{w^{*}}{\theta^{*}} c_{2}\left(\pi_{11}^{*}+1\right)+\frac{w^{*}}{\theta^{*}} c_{2}^{*}+z\right] \pi_{21}
\end{aligned}
$$




$$
\begin{aligned}
& \frac{\theta}{p_{2}} \frac{d p_{2}}{d \theta}=\frac{\theta}{p_{2}^{*}} \frac{d p_{2}^{*}}{d \theta}+\frac{\theta}{\left(1+i^{*}\right)} \frac{d i^{*}}{d \theta}+\frac{\theta}{e} \frac{d e}{d \theta} \\
& =A\left\{\frac{w^{*}}{\theta^{*}} c_{2}\left[\frac{w}{\theta} c_{1}+2 \frac{w}{\theta} c_{1}^{*}+z^{*}\right] \pi_{21}\left(\pi_{11}^{*}+1\right)\right. \\
& \left.+\left(\frac{w^{*}}{\theta^{*}} c_{2}^{*}+z\right)\left[\left(\frac{w}{\theta} c_{1}+z^{*}\right)\left(\pi_{21}+\pi_{12}^{*}\right)+\frac{w}{\theta} c_{1}^{*}\left(\pi_{12}^{*}\left(\pi_{22}+1\right)+2 \pi_{21}\right)\right]\right\} \\
& \frac{\theta}{p_{1}^{*}} \frac{d p_{1}^{*}}{d \theta}=\frac{\theta}{p_{1}} \frac{d p_{1}}{d \theta}+\frac{\theta}{(1+i)} \frac{d i}{d \theta}-\frac{\theta}{e} \frac{d e}{d \theta} \\
& =A\left\{\frac{w^{*}}{\theta^{*}} c_{2}\left[2\left(\frac{w}{\theta} c_{1}+z^{*}\right)+\frac{w}{\theta} c_{1}^{*}\left(\pi_{22}+1\right)\left(3-\pi_{11}^{*}\right)\right]\right. \\
& \left.+\left(\frac{w^{*}}{\theta^{*}} c_{2}^{*}+z\right)\left[\frac{w}{\theta} c_{1}+\frac{w}{\theta} c_{1}^{*}\left(\pi_{22}+1\right)+z^{*}\right]\right\} \\
& \frac{\theta}{\left(\frac{p_{2}}{p_{1}}\right)} \frac{d\left(\frac{p_{2}}{p_{1}}\right)}{d \theta}=\frac{\theta}{p_{2}} \frac{d p_{2}}{d \theta}-\frac{\theta}{p_{1}} \frac{d p_{1}}{d \theta} \\
& =-A\left[\frac{w^{*}}{\theta^{*}} c_{2}\left(\pi_{11}^{*}+1\right)+\frac{w^{*}}{\theta^{*}} c_{2}^{*}+z\right]\left[\frac{w}{\theta} c_{1}+2 \frac{w}{\theta} c_{1}^{*}+z^{*}\right] \\
& \frac{\theta}{\left(\frac{p_{2}^{*}}{p_{1}^{*}}\right)} \frac{d\left(\frac{p_{i}^{*}}{p_{1}^{*}}\right)}{d \theta}=\frac{\theta}{p_{2}^{*}} \frac{d p_{2}^{*}}{d \theta}-\frac{\theta}{p_{1}^{*}} \frac{d p_{1}^{*}}{d \theta} \\
& =-A\left\{\frac{w^{*}}{\theta^{*}} c_{2}\left[\frac{w}{\theta} c_{1}+2 \frac{w}{\theta} c_{1}^{*}+z^{*}\right]\left(\pi_{11}^{*}+1\right)\right. \\
& \left.+\left(\frac{w^{*}}{\theta^{*}} c_{2}^{*}+z\right)\left[\frac{w}{\theta} c_{1}+\frac{w}{\theta} c_{1}^{*}\left(\pi_{22}+1\right)+z^{*}\right]\right\} \\
& \frac{\theta}{p_{1} c_{1}} \frac{d\left(p_{1} c_{1}\right)}{d \theta}=\pi_{12}\left[\frac{\theta}{p_{2}} \frac{d p_{2}}{d \theta}-\frac{\theta}{p_{1}} \frac{d p_{1}}{d \theta}\right] \\
& \frac{\theta}{p_{2} c_{2}} \frac{d\left(p_{2} c_{2}\right)}{d \theta}=-\pi_{21}\left[\frac{\theta}{p_{2}} \frac{d p_{2}}{d \theta}-\frac{\theta}{p_{1}} \frac{d p_{1}}{d \theta}\right] \\
& \frac{\theta}{p_{1}^{*} c_{1}^{*}} \frac{d\left(p_{1}^{*} c_{1}^{*}\right)}{d \theta}=\pi_{12}^{*}\left[\frac{\theta}{p_{2}^{*}} \frac{d p_{2}^{*}}{d \theta}-\frac{\theta}{p_{1}^{*}} \frac{d p_{1}^{*}}{d \theta}\right] \\
& \frac{\theta}{p_{2}^{*} c_{2}^{*}} \frac{d\left(p_{2}^{*} c_{2}^{*}\right)}{d \theta}=-\pi_{21}^{*}\left[\frac{\theta}{p_{2}^{*}} \frac{d p_{2}^{*}}{d \theta}-\frac{\theta}{p_{1}^{*}} \frac{d p_{1}^{*}}{d \theta}\right] \\
& \frac{\theta}{p_{1} c_{1}^{*}} \frac{d\left(p_{1} c_{1}^{*}\right)}{d \theta}=\frac{\theta}{p_{1}^{*} c_{1}^{*}} \frac{d\left(p_{1}^{*} c_{1}^{*}\right)}{d \theta}-\frac{\theta}{(1+i)} \frac{d i}{d \theta}+\frac{\theta}{e} \frac{d e}{d \theta} \\
& =A\left\{\frac { w ^ { * } } { \theta ^ { * } } c _ { 2 } \left[\left(\frac{w}{\theta} c_{1}+z^{*}\right)\left(\pi_{12}^{*}\left(\pi_{22}-\pi_{11}^{*}\right)+2 \pi_{21}\right)\right.\right. \\
& \left.+\frac{w}{\theta} c_{1}^{*}\left(2 \pi_{12}^{*}\left(\pi_{22}-\pi_{11}^{*}\right)+\pi_{21}\left(\pi_{11}^{*}+1\right)\right)\right] \\
& \left.+\left(\frac{w^{*}}{\theta^{*}} c_{2}^{*}+z\right)\left(\frac{w}{\theta} c_{1}+\frac{w}{\theta} c_{1}^{*}+z^{*}\right) \pi_{21}\right\}
\end{aligned}
$$




$$
\begin{aligned}
\frac{\theta}{p_{2}^{*} c_{2}} \frac{d\left(p_{2}^{*} c_{2}\right)}{d \theta}= & \frac{\theta}{p_{2} c_{2}} \frac{d\left(p_{2} c_{2}\right)}{d \theta}-\frac{\theta}{\left(1+i^{*}\right)} \frac{d i^{*}}{d \theta}-\frac{\theta}{e} \frac{d e}{d \theta} \\
= & -A\left[\frac{w^{*}}{\theta^{*}} c_{2}+\frac{w^{*}}{\theta^{*}} c_{2}^{*}+z\right]\left[\frac{w}{\theta} c_{1}+\frac{w}{\theta} c_{1}^{*}\left(\pi_{22}+1\right)+z^{*}\right] \pi_{12}^{*} \\
\frac{d l^{*}}{d \theta}= & -\frac{1}{w^{*}} \frac{d\left(p_{2}^{*} c_{2}\right)}{d \theta} \\
\frac{d l}{d \theta}= & -\frac{1}{w} \frac{d\left(p_{1} c_{1}^{*}\right)}{d \theta} \\
\frac{\theta}{c_{2}} \frac{d c_{2}}{d \theta}= & \frac{\theta}{p_{2} c_{2}} \frac{d\left(p_{2} c_{2}\right)}{d \theta}-\frac{\theta}{p_{2}} \frac{d p_{2}}{d \theta} \\
= & -A\left[\frac{w^{*}}{\theta^{*}} c_{2}^{*}+z\right]\left[\frac{w}{\theta} c_{1}+\frac{w}{\theta} c_{1}^{*}\left(\pi_{22}+1\right)+z^{*}\right] \pi_{12}^{*} \\
\frac{\theta}{c_{2}^{*}} \frac{d c_{2}^{*}}{d \theta}= & \frac{\theta}{p_{2}^{*} c_{2}^{*}} \frac{d\left(p_{2}^{*} c_{2}^{*}\right)}{d \theta}-\frac{y}{p_{2}^{*}} \frac{d p_{2}^{*}}{d \theta} \\
= & A\left\{\frac{w^{*}}{\theta^{*}} c_{2}\left[\left(\frac{w}{\theta} c_{1}+z^{*}\right)\left(\pi_{21}^{*}\left(\pi_{11}^{*}+1\right)+\pi_{12}^{*}\right)+\frac{w}{\theta} c_{1}^{*}\left(2 \pi_{21}^{*}+\left(\pi_{22}+1\right) \pi_{12}^{*}\right)\right]\right. \\
& \left.+\left(\frac{w^{*}}{\theta^{*}} c_{2}^{*}+z\right)\left[\frac{w}{\theta} c_{1}+\frac{w}{\theta} c_{1}^{*}\left(\pi_{22}+1\right)+z^{*}\right] \pi_{21}^{*}\right\} \\
\frac{\theta}{c_{1}} \frac{d c_{1}}{d \theta}= & \frac{\theta}{p_{1} c_{1}} \frac{d\left(p_{1} c_{1}\right)}{d \theta}-\frac{\theta}{p_{1}} \frac{d p_{1}}{d \theta} \\
= & A\left\{\frac{w^{*}}{\theta^{*}} c_{2}\left[\frac{w}{\theta} c_{1}+2 \frac{w}{\theta} c_{1}^{*}+z^{*}\right]\left(\pi_{11}^{*}+1\right) \sigma\right. \\
& \left.+\left(\frac{w^{*}}{\theta^{*}} c_{2}^{*}+z\right)\left[\left(\frac{w}{\theta} c_{1}+z^{*}\right) \sigma+\frac{w}{\theta} c_{1}^{*}\left(\left(\pi_{22}+1\right)\left(\pi_{12}^{*}+\pi_{22}\right)+\left(1-\pi_{12}\right) \pi_{21}\right)\right]\right\} \\
\frac{\theta}{c_{1}^{*}} \frac{d c_{1}^{*}}{d \theta}= & \frac{\theta}{p_{1}^{*} c_{1}^{*}} \frac{d\left(p_{1}^{*} c_{1}^{*}\right)}{d \theta}-\frac{y}{p_{1}^{*}} \frac{d p_{1}^{*}}{d \theta} \\
= & -A\left\{\frac{w^{*}}{\theta^{*}} c_{2}\left[\left(\frac{w}{\theta} c_{1}+z^{*}\right)\left(\pi_{11}^{*}{ }^{2}+1\right)+\frac{w}{\theta} c_{1}^{*}\left(\pi_{22}+1\right)\left(\pi_{11}^{*}+1\right)\right]\right. \\
& \left.+\left(\frac{w}{\theta} c_{1}+\frac{w}{c_{1}^{*}}\left(\pi_{22}+1\right)+z^{*}\right] \pi_{11}^{*}\right\} \\
= &
\end{aligned}
$$




\section{Lump Sum Transfers (x)}

$$
\begin{aligned}
& 1+x=(2+i)\left[\frac{w}{\theta} c_{1}+\frac{w}{\theta} c_{1}^{*}\right]+(1+i) z^{*}-y \\
& \frac{(1+x)}{e} \frac{d e}{d x}=A\left\{\pi_{12}^{*}\left[2(1+x)-\frac{w}{\theta} c_{1}\left(1-\pi_{12}\right)-2 \frac{w}{\theta} c_{1}^{*}-z^{*}\right]\left[2 \frac{w^{*}}{\theta^{*}} c_{2}+\frac{w^{*}}{\theta^{*}} c_{2}^{*}+z\right]\right. \\
& +\pi_{21}\left[3(1+x)-\frac{w}{\theta} c_{1}-2 \frac{w}{\theta} c_{1}^{*}-z^{*}\right]\left[\frac{w^{*}}{\theta^{*}} c_{2} \pi_{12}^{*}\right] \\
& \left.+\pi_{21}\left[1+x-\frac{w}{\theta} c_{1}-\frac{w}{\theta} c_{1}^{*}\left(\pi_{11}^{*}+1\right)-z^{*} \pi_{11}^{*}\right]\left[2 \frac{w^{*}}{\theta^{*}} c_{2}+\frac{w^{*}}{\theta^{*}} c_{2}^{*}+z\right]\right\} \\
& \frac{(1+x)}{p_{1}} \frac{d p_{1}}{d x}=A\left\{\frac{w^{*}}{\theta^{*}} c_{2}\left[1+x-\frac{w}{\theta} c_{1}-2 \frac{w}{\theta} c_{1}^{*}-z^{*}\right] \pi_{22}\left(\pi_{11}^{*}+1\right)\right. \\
& \left.+\left(\frac{w^{*}}{\theta^{*}} c_{2}^{*}+z\right)\left[\left(1+z-\frac{w}{\theta} c_{1}-2 \frac{w}{\theta} c_{1}^{*}-z^{*}\right)\left(\pi_{22}+\pi_{12}^{*}\right)-\frac{w}{\theta} c_{1}^{*} \pi_{21} \pi_{12}^{*}\right]\right\} \\
& \frac{(1+x)}{p_{2}^{*}} \frac{d p_{2}^{*}}{d x}=\frac{(1+x)}{\left(1+i^{*}\right)} \frac{d i^{*}}{d x} \\
& =-A \frac{w^{*}}{\theta^{*}} c_{2}\left[\left(1+x-\frac{w}{\theta} c_{1}^{*}\right)\left(1+\pi_{22}\right)-\frac{w}{\theta} c_{1}\left(1-\pi_{12}\right)-z^{*} \pi_{22}\right] \pi_{12}^{*} \\
& \frac{(1+x)}{(1+i)} \frac{d i}{d x}=\frac{(1+x)}{p_{1}} \frac{d p_{1}}{d x}-1 \\
& =A\left\{\frac{w^{*}}{\theta^{*}} c_{2}\left[(1+x) \pi_{22}-\frac{w}{\theta} c_{1}^{*} \pi_{21}\right]\left(1+\pi_{11}^{*}\right)\right. \\
& \left.+\left(\frac{w^{*}}{\theta^{*}} c_{2}^{*}+z\right)\left[(1+x)\left(\pi_{21}+\pi_{11}^{*}\right)-\frac{w}{\theta} c_{1}^{*} \pi_{21}\right]\right\}
\end{aligned}
$$




\section{References}

[1] Backus, D.K., P.J. Kehoe, and F. Kydland (1991): "International Real Business Cycles," Working Paper No.426R, Federal Reserve Bank of Minneapolis Research Department.

[2] Bernanke, B. and A. Blinder (1990): "The Federal Funds Rate and the Channels of Monetary Transmission," Working Paper No.3487, National Bureau of Economics Research.

[3] Cantor, R. and N. C. Mark (1987): "International Debt and World Business Fluctuations," Journal of International Money and Finance, Vol.6, pp.153-165.

[4] Cantor, R. and N. C. Mark (1988): "The International Transmission of Real Business Cycles," International Economic Review, Vol.29, No.3, pp.493-507.

[5] Christiano, L. J. (1991): "Modeling the Liquidity Effect of A Money Shock," Federal Reserve Bank of Minneapolis Quarterly Review, Vol.15, No.1, pp.1-34.

[6] Christiano, L. J. and M. Eichenbaum (1991): "Liquidity Effects, Monetary Policy and the Business Cycle," working paper, Northwestern University.

[7] Cooley, T. F. and G. D. Hansen (1989) : "The Inflation Tax in a Real Business Cycle Model," American Economic Review, Vol.79, pp.733-748.

[8] Dellas, H. (1986): “A Real Model of the World Business Cycle," Journal of International Money and Finance, Vol.5, pp.381-394.

[9] Devereux, M. B., A. W. Gregory and G. W. Smith (1990): "Realistic Cross-Country Consumption Correlations in a Two-Country, Equilibrium, Business Cycle Model, Journal of International Money an Finance, Vol.11, pp.3-16.

[10] Fuerst, T. S. (1992): "Liquidity, Loanable Funds, and Real Activity," Journal of Monetary Economics, Vol.29, pp.3-24.

[11] Greenwood, J and G. W. Huffman (1987): "A Dynamic Equilibrium Model of Inflation and Unemployment," Journal of Monetary Economics, Vol.19, pp.203-228.

[12] Grossman, S. and L. Weiss (1983): "A Transactions-Based Model of the Monetary Transmission Mechanism," American Economic Review, Vol.73, pp.871-880.

[13] Helpman, E. and A. Razin (1982): "A Comparison of Exchange Rate Regimes in the Presence of Imperfect Capital Markets," International Economic Review, Vol.23, No.2, pp.365-388.

[14] Helpman, E. and A. Razin (1985): "Floating Exchange Rates with Liquidity Constraints in Financial Markets," Journal of International Economics, Vol.19, pp.99-117.

[15] Lucas, R. E., Jr. (1978): “Asset Prices in an Exchange Economy," Econometrica, Vol.46, pp.1429-1445.

[16] Lucas, R. E., Jr. (1982): "Interest Rates and Currency Prices in a Two-country World," Journal of Monetary Economics, Vol.10, pp.335-359. 
[17] Lucas, R. E., Jr. (1990): “Liquidity and Interest Rates," Journal of Economic Theory, Vol.50, pp.237-264.

[18] Rotemberg, J. J. (1984): “A Monetary Equilibrium Model with Transactions Costs," Journal of Political Economy, Vol.92, pp.41-58.

[19] Rotemberg, J. J. (1985): "Money and the Terms of Trade," Journal of International Economics, Vol.19, pp.141-160.

[20] Stockman, A. C. (1980): "A Theory of Exchange Rate Determination," Journal of Political Economy, Vol.88, No.4, pp.673-698.

[21] Stockman, A. C. and L. L. Tesar (1990): "Tastes and Technology in a Two-Country Model of the Business Cycle: Explaining International Comovements," Working Paper No.255, Rochester Center for Economics Research.

[22] Tesar, L. L. (1990): "International Risk-Sharing and Nontraded Goods," Working Paper in Economics No.15-90, University of California, Santa Barbara.

[23] Svensson, L. E. O. (1985): "Currency Prices, Terms of Trade, and Interest Rates," Journal of International Economics, Vol.18, pp.17-41.

[24] Svensson, L. E. O. and S. van Wijnbergen (1989) : "Excess Capacity, Monopolistic Competition, and International Transmission of Monetary Disturbances," Economic Journal, Vol.99, pp.785-805. 